PROF. OSVALDO D. UCHITEL (Orcid ID : 0000-0002-8909-6787)

Article type : Review Article

\title{
Synaptic signals mediated by protons and acid sensing ion channels
}

Osvaldo D. Uchitel, Carlota González Inchauspe and Carina Weissmann

Instituto de Fisiología, Biología molecular y Neurociencias (IFIBYNE) CONICET. Departamento de Fisiología, Biología Molecular y Celular "Dr. Héctor Maldonado", Facultad de Ciencias Exactas y Naturales, Universidad de Buenos Aires. Ciudad Universitaria. (C1428EGA) Ciudad Autónoma de Buenos Aires, Argentina.

Correspondence should be addressed to Dr. Osvaldo D. Uchitel

E-mail: ouchitel@gmail.com

Instituto de Fisiología, Biología molecular y Neurociencias (IFIBYNE) UBA-CONICET

Facultad de Ciencias Exactas y Naturales. Edificio IFIBYNE Ciudad Universitaria. (C1428EGA) Ciudad Autónoma de Buenos Aires, Argentina.

Phone: (+54-11) 45763368

FAX: (+54-11) 45763321

\section{Acknowledgments}

This work was supported by PICT 2016-3642 from Agencia Nacional de Promoción Científica y Tecnológica (ANPCYT) and UBACYT 01/Q666 (20020130100666BA) from University of Buenos Aires granted to Dr O.D. Uchitel.

\begin{abstract}
Extracellular $\mathrm{pH}$ changes may constitute significant signals for neuronal communication. During synaptic transmission, changes in $\mathrm{pH}$ in the synaptic cleft take place. Its role in the regulation of presynaptic $\mathrm{Ca}^{2+}$ currents through multivesicular release in ribbon type synapses is a proven phenomenon. In recent years, protons have been recognized as neurotransmitters that This article has been accepted for publication and undergone full peer review but has not been through the copyediting, typesetting, pagination and proofreading process, which may lead to differences between this version and the Version of Record. Please cite this article as doi: $10.1002 /$ syn. 22120
\end{abstract}

This article is protected by copyright. All rights reserved. 
participate in neuronal communication in synapses of several regions of the CNS like the amygdala, nucleus accumbens and brainstem. Protons are released by nerve stimulation and activate postsynaptic acid sensing ion channels (ASICs). Several types of ASICs channels are expressed in the peripheral and central nervous system. The influx of $\mathrm{Ca}^{2+}$ through some subtypes of ASICs, as a result of synaptic transmission, agrees with the participation of ASICS in synaptic plasticity. Pharmacological and genetical inhibition of ASIC1a results in alterations in learning, memory and phenomena like fear and cocaine-seeking behavior. The recognition of endogenous molecules like arachidonic acid, cytokines, histamine, spermine, lactate and neuropeptides, capable of inhibiting or potentiating ASICs suggests the existence of mechanisms of synaptic modulation that have not yet been fully identified and that could be tuned by new emerging pharmacological compounds with potential therapeutic benefits.

\section{Keywords}

Synaptic transmission, Protons, Acid sensing ion channels, Synaptic modulation, Synaptic plasticity

\section{INTRODUCTION}

The physiological activity of the neurons involves processes that cause changes in $\mathrm{pH}$; thus, it is expected that there are mechanisms that sense and use this information to regulate the activity of the nervous system (Chesler, 2003). During the last few years, the role of protons as neurotransmitters and their receptors, the acid sensing ion channels (ASICs), in neuronal communication and synaptic plasticity has been recognized. The objective of this review is to provide an up-to-date overview of the protonergic neurotransmission, and the role of the protongated channels involved in synaptic transmission.

\section{EVIDENCE FOR PH CHANGES IN THE SYNAPTIC CLEFT}

Given the sensitivity of many ion channels to hydrogen ions, the modulation of local $\mathrm{pH}$ might influence brain function, particularly where $\mathrm{pH}$ shifts are sufficiently large and rapid. Considerable effort has been made to quantify extracellular $\mathrm{pH}$ shifts in the central nervous system (CNS). The first data on the kinetics of $\mathrm{pH}$ changes during and after electrical activation were recorded in cat brain cortex by means of $\mathrm{H}^{+}$-sensitive glass microelectrodes (tip diameters of 1-4 $\mu \mathrm{m}$ ) by Urbanics, LenigerFollert, \& Lubbers in 1978. More recently, using high speed pH electrodes, Fedirko, Svichar, \& Chesler, (2006) and Makani and Chesler, (2010a, b) have postulated that a rise in extracellular pH evoked by neural activity is generated by the plasma membrane calcium ATPase. Acidification, due to the activity of glial cells has also been suggested (Rose and Deitmer, 1994). A vast majority of 
studies on $\mathrm{pH}$ changes in the CNS were performed with electrodes inserted into the brains of anesthetized animals or in ex vivo brain slices. The electrodes sense a $\mathrm{pH}$ change filtered in amplitude and time course and are thus far from reflecting the changes that occur near the cell membrane or in the synaptic space. Therefore, direct measurements of $\mathrm{pH}$ changes at the synaptic cleft are scarce and limited to synaptic contacts.

Proton concentration at the synaptic cleft will initially depend on the $\mathrm{pH}$ and buffer capacity of the extracellular space that is directly connected to. The synaptic cleft has a limited volume and is subjected to changes in the proton concentration due to one or more transmembrane fluxes generating $\mathrm{pH}$ shifts in the same or in opposite direction. Furthermore, the synaptic cleft is bombarded by spontaneous or action potentials evoked by the fusion of synaptic vesicles. It is known that vesicular pH is low (Anderson and Orci, 1988; Miesenbock, De Angelis, \& Rothman, 1998) as a result of $\mathrm{H}^{+}$-ATPase activity which generates an electrochemical gradient that drives transport of neurotransmitters into the vesicle (Y. Liu and Edwards, 1997). Furthermore, vesicular acidification is lost and regained after endocytosis (Miesenbock et al., 1998), consistent with the release of protons into the synaptic cleft. Therefore, during exocytosis protons are released together with neurotransmitters into the synaptic cleft.

Evidence of acidification as a result of vesicle fusion comes from experiments in hippocampal slices that used phenol red as a pH indicator (Krishtal, Osipchuk, Shelest, \& Smirnoff, 1987). In those experiments, the acidification produced by a volley of spikes was blocked by an increase in $\mathrm{Mg}^{2+}$ concentration suggesting that this was the results of blocking $\mathrm{Ca}^{2+}$ influx responsible for neurotransmitter release. However, since the acidification was measured not strictly at the synaptic cleft, the observed changes could be a consequence of higher neuronal activity and not from a $\mathrm{pH}$ drop at the cleft.

Interestingly, Cho and von Gersdorff, (2014) calculated how many protons can be released from a fused vesicle. It is an approximate but clarifying calculation that determines, on average, there is less than 1 free proton per vesicle. However, considering the vesicle glutamate concentration (12002400 molecules per vesicle) and the pk of glutamate (pK 4.1), according to the HendersonHassselbalch equation, a change from pH 5.5 inside the synaptic vesicle to 7.3 at the extracellular media results in de-protonation of 46 to 92 glutamic acid molecules. However, until now, the impact of vesicle exocytosis on the cleft $\mathrm{pH}$ has not been measured with good amplitude and time resolution in a direct way. Furthermore, it is difficult to estimate the possible $\mathrm{pH}$ variations due to different processes that take place after the opening of the synaptic vesicles into the cleft, such as deprotonation of synaptic vesicle luminal proteins and neurotransmitters, persistence of $\mathrm{H}^{+}$-ATPase activity, and hydrolysis of ATP generating an additional phosphate buffer. Furthermore, if $\mathrm{pH}$ 
changes during synaptic transmission due to vesicle exocytosis, a gradient should be expected with a stronger variation close to the presynaptic membrane.

In the visual system, the sensitivity of calcium channels to $\mathrm{pH}$ was used to estimate $\mathrm{pH}$ changes at the synaptic cleft. Studying calcium-activated chloride currents in cone photoreceptors, Barnes and Bui (1991) have proposed that the $\mathrm{pH}$ modulation of the chloride current is accounted for by the $\mathrm{pH}$ sensitivity of $\mathrm{Ca}^{2+}$ channel activation and permeation as already characterized in other cells (Klockner and Isenberg, 1994; Catterall, 2000). Furthermore, they speculated that $\mathrm{pH}$-induced shift in $\mathrm{Ca}^{2+}$ channel gating could affect $\mathrm{Ca}^{2+}$-dependent transmitter release. Indeed, the cone photoreceptor synapse has numerous vesicle fusion sites and $\mathrm{Ca}^{2+}$ channels are clustered together. Using this preparation, DeVries (2001) was able to demonstrate the inhibition exerted by the release of protons on the presynaptic $\mathrm{Ca}^{2+}$ currents, confirming a previous proposal of a feed-back mechanism mediated by the released protons acting on presynaptic $\mathrm{Ca}^{2+}$ channels linked to transmitter release (Barnes, Merchant, \& Mahmud, 1993).

Palmer and colleagues followed the proton- $\mathrm{Ca}^{2+}$ channels feedback hypothesis working on bipolar cell terminals in slices of goldfish retina. They estimated that the release of vesicular protons during exocytosis causes an acidification of the synaptic cleft from 7.5 to 6.9 and is modulated by the concentration of the extracellular buffer so that increasing the buffer capacity from 3 to $10 \mathrm{mM}$ Hepes blocks the $\mathrm{pH}$ driven inhibition of the $\mathrm{Ca}^{2+}$ current. They also demonstrated that acidification under physiological buffering conditions produces a $\mathrm{Ca}^{2+}$ current inhibition after the initial exocytosis which could in turn decrease subsequent exocytosis events. Furthermore, the space restrictions set by the width of the synaptic cleft seems to affect $\mathrm{pH}$ changes since $\mathrm{Ca}^{2+}$ current inhibition is negligible in acutely dissociated bipolar cell terminals (Palmer, Hull, Vigh, \& von Gersdorff, 2003).

In the auditory system, a transient block of $\mathrm{Ca}^{2+}$ current due to acidification of the synaptic cleft was found in bullfrog mature hair cell ribbon synapses during multivesicular release (Cho \& von Gersdorff, 2014). This modulation takes place in synapses from mature animals where a compact active-zone topography with $\mathrm{Ca}^{2+}$ channel rows flanked by two rows of docked vesicles is present. Recently, the same research group found similar features at the mammalian hair cell ribbon synapse (Vincent et al., 2018). The mature synapses show a robust $\mathrm{Ca}^{2+}$ current transient blocked by protons at post hearing age. In contrast, the immature synapses do not show the $\mathrm{Ca}^{2+}$ current block by protons, have a non-compact active zone and $\mathrm{Ca}^{2+}$ channels and are loosely coupled to the release site.

Much less is known about $\mathrm{pH}$ changes during synaptic transmission at non-ribbon synapses. At central synapses, like the calyx of Held, $\mathrm{Ca}^{2+}$ current inhibition by protons release has not been detected (Cho and von Gersdorff, 2014). At such synapses, with hundreds of disperse active zone, 
exocytosis is evoked by a rapid deactivation of $\mathrm{Ca}^{2+}$ currents in response to invading action potentials; and normally involves the release of only one or a few vesicles at each active zone (Meyer, Neher, \& Schneggenburger, 2001; Taschenberger at al 2002).

In hippocampal brain slices, Makani and Chesler $(2007,2010 \mathrm{~b})$ have demonstrated that activation of the Schaffer collaterals generates an extracellular alkaline transient both, in vitro and in vivo, which may provide relief of the $\mathrm{H}^{+}$block of NMDA receptors and thereby increase excitability. On the contrary, during GABAergic transmission, a physiological acidification of the synaptic cleft due to the activity of the $\mathrm{Na}^{+} / \mathrm{H}^{+}$exchanger transporter has been reported (Dietrich and Morad, 2010).

One of the most direct evidence of changes in extracellular $\mathrm{pH}$ due to synaptic stimulation in fast conventional synapses was reported by Du et al. (2014) using a pH-sensitive superecliptic pHluorin fused to the extracellular domain of a postsynaptic membrane protein. Upon stimulation, transfected pyramidal neurons transiently reduced the $\mathrm{pH}$ at spines and the neighboring dendrites, followed by a slower alkalinization. The extent of acidification and alkalinization depended on the frequency of stimulation. The alkalinization that followed the transient acidification has been reported in other preparations (Chesler, 2003)

Neurotransmitter levels within the synaptic cleft rise and fall very rapidly, with clearance times generally on the order of a few hundred microseconds to 2 ms (Clements, 1996). Currently, the time course of $\mathrm{pH}$ changes at fast synapses has not been measured in detail, but from indirect estimations at ribbon-type and hippocampal synapses (Palmer et al., 2003) (Du et al., 2014), it is possible to hypothesize that the synaptic cleft $\mathrm{pH}$ waveform is complex, including an acid and alkaline shift with a time course that depends on the buffer capacity of the cleft. The resulting change in extracellular $\mathrm{pH}$ is, therefore, likely to be much smaller than at ribbon synapses but sufficient to inhibit AMPA receptors by enhancing desensitization (Traynelis and Cull-Candy, 1991; Lei, Orser, Thatcher, Reynolds, \& MacDonald, 2001); and to activate ASICs and generate a postsynaptic current as shown by Du et al. (2014) at the amygdala; Kreple et al. (2014) at the nucleus accumbens and by our group at the mouse calyx of Held (González-Inchauspe, Urbano, Di Guilmi \& Uchitel, 2017) confirmed recently by Lujan B, Dagostin A, von Gersdorff H. (2019),(Fig 1A). Furthermore, cleft pH can also remain acidic during prolonged stimulation or during a variety of pathological conditions such as during epileptic activity.

\section{PROTON RECEPTORS AND ASIC CHANNELS}

Protons modulate a very large number of molecules in different tissues and organs. Within the molecules involved in synaptic transmission, several fundamental proteins for neuronal communication have been reported to be modulated positively or negatively by proton increase in the extracellular medium. However, until today, only a few types of channel/receptors were 
identified with protons specifically acting as agonists; these are the family of ASICs (Waldmann et al, 1997) and the TRPV1 (transient potential receiver vanilloid 1), (Ree et al., 2001). On the other hand, an important family of metabotropic receptors of protons (coupled to G proteins), Proton-sensing Gprotein-coupled receptors, have been recognized and have a broad expression mainly in organs and tissues outside the CNS (Ludwig MG et al 2003).

Synaptic ion channels modulated by protons.

Protein function is sensitive to alterations in $\mathrm{pH}$ and thus changes in $\mathrm{pH}$ can impact on the release of synaptic vesicles, which depends on the concerted action of a complex machinery of different proteins (for review see Südhof TC. 2012). Presynaptic calcium concentration changes mediated via voltage-gated calcium channels (Neher \& Taschenberger 2013) are pH dependent and in some synapses modulates transmitter release as described in the previous section.

Extracellular protons inhibit NMDA receptor function with an IC50 of $\sim 50 \mathrm{nM}$, corresponding to a pH of 7.3 (Traynelis \& Cull-Candy, 1990; for review see Hansen et al 2018). Proton inhibition proceeds identically in the absence or presence of agonist, which rules out the possibility that protonation inhibits receptors by altering co-agonist binding (Banke et al 2005). Thus, neuronal NMDA receptors are tonically inhibited by protons at physiological $\mathrm{pH}$ and are therefore able to respond to small changes in extracellular $\mathrm{pH}$ that can occur under physiological and pathological conditions. In contrast, properties of AMPA- receptors are only slightly modulated by alterations of extracellular pH (Lei et al 2001), so AMPA or kainate receptor mediated responses remain unchanged at all physiological pH levels (Traynelis \&, Cull-Candy 1991).

Acid sensing ion channels

ASICs, also called proton-gated channels (Waldmann, Champigny, Bassilana, Heurteaux, \& Lazdunski, 1997) play an important role in signal transduction as an exquisite proton sensor in the nervous system (for an extensive review see Cristofori-Armstrong and Rash, 2017; Grunder and Pusch, 2015; Kellenberger and Schild, 2015 ; Wemmie, Taugher, \& Kreple, 2013).

ASICs form a family of channels that belong to the degenerin/epithelial $\mathrm{Na}^{+}$channel gene family (Kellenberger and Schild, 2015), an evolutionarily conserved gene family (Lynagh, Mikhaleva, Colding, Glover, \& Pless, 2018). In rodents and humans, five genes, including ASIC 1-5 (Accn1-5) encode at least seven ASICs subtypes, ASICs (1a, 1b, 2a, 2b, 3, 4 and 5) (Kellenberger and Schild, 2015; Lin, Chiang, \& Chen, 2015). Functional ASICs are formed by three subunits (Carnally et al., 2008). The subunits that form these channels share a common structure with two alpha-helix transmembrane segments (TM1 and TM2) which line the ion pore, a large extracellular part (approx. 370 amino acids) and a short cytoplasmic tail (35-90 amino acids) (Fig. 2). The extracellular part is where ligands most likely bind. The crystal structure of chicken ASIC1 has revealed the three- 
dimensional organization formed by 12 beta-sheets and 7 alpha helices (Jasti, Furukawa, Gonzales, and Gouaux, 2007).

Single ASIC subunits shape resembles a hand holding a small ball and thus, the domains have been named accordingly. The palm domain forms the internal scaffold of the channel along the central vertical axis. The thumb and the finger point toward the exterior of the channel and enclose, together with the $\beta$-ball, the "acidic pocket" (AcP) (Fig. 2) (Jasti et al., 2007). Due to the presence of many acidic residues, the AcP was initially proposed to be a pH sensor (Jasti et al., 2007). However, $\mathrm{H}^{+}$-sensing residues have also been identified outside the AcP (Krauson, Rued, and Carattino, 2013; Liechti et al., 2010; Paukert, Chen, Polleichtner, Schindelin, \& Grunder, 2008). Nevertheless, its importance is underlined by the fact that it constitutes the binding site of several ASIC-specific toxins (Baconguis and Gouaux, 2012; Mourier et al., 2016).

ASIC subunits can assemble into functional homomeric channels: ASIC1a, ASIC1b, ASIC2a, and ASIC3; and with the inclusion of ASIC2b they can form heterotrimeric channels in different combinations. (Bassler, Ngo-Anh, Geisler, Ruppersberg, \& Grunder, 2001; Bartoi, Augustinowski, Polleichtner, Grunder, \& Ulbrich, 2014; Hesselager, Timmermann, \& Ahring, 2004; Jasti et al., 2007; Waldmann, Bassilana, et al., 1997; Waldmann, Champigny, et al., 1997). Homomeric ASIC1a, and heteromeric ASIC1a/ASIC2a or ASIC1a/ASIC2b show widespread expression throughout the central and peripheral nervous systems, whereas ASIC1b and ASIC3 are largely restricted to the peripheral nervous system (Askwith, Wemmie, Price, Rokhlina, \& Welsh, 2004); Baron et al., 2002; Baron, Voilley, Lazdunski, \& Lingueglia, 2008; Benson et al., 2002 ; Hattori et al., 2009; Lin et al., 2015; Waldmann, Bassilana, et al., 1997; L. J. Wu et al., 2004).

ASIC1 is broadly expressed in many areas of the brain and the levels of expression do not vary significantly among neurons with very diverse functional specialization or localization, (Waldmann et al. 1997, Alvarez de la Rosa et al., 2003). Within neurons, ASIC1 was found predominantly on the plasma membrane of the soma and, to a lesser degree, over the dendrites and axons. However, Wemmie et al. (2002), have shown that ASIC colocalizes with PSD-95 in hippocampal neurons and it is enriched in synaptosome subcellular fractions. Immunohistochemistry studies have shown that the ASIC1 signal was slightly punctate which may reflect clustering of ASIC1 by protein interacting with anchoring proteins like PICK 1, protein interacting with C kinase 1 (Hruska-Hageman et al. 2002). Furthermore, using organotypic hippocampal slices and biolistic transfection, Zha et al, (2006) found that ASIC1a was localized in dendritic spines where it functions as a proton receptor.

Functionally, ASICs span a wide $\mathrm{pH}$ range, from $\mathrm{pH} 4$ to $\mathrm{pH}$ 8. (table 1). Homomeric ASIC1a and ASIC3 have a high proton sensitivity (EC50 pH 6.5); homomeric ASIC1b and ASIC 2a have a lower proton 
sensitivity and ASIC4 lost its sensitivity during evolution (Lynagh et al., 2018). ASIC5 channels are not activated by protons but by bile acids, leading to the denomination of BASIC (Lefevre et al., 2014).

Developmental changes in the electrophysiological and pharmacological properties of acid-sensing ion channels in CNS neurons were described and attributed to an increase in the ratio of ASIC2/ASIC1 mRNA with neuronal maturation. (Li, Kratzer, Inoue, Simon \& Xiong, 2010).

ASICs are more permeable to $\mathrm{Na}^{+}$than $\mathrm{K}^{+}\left(\mathrm{PNa}^{+} / \mathrm{PK}^{+}\right.$range 5-14) (Bassler et al., 2001; Hoagland, Sherwood, Lee, Walker, \& Askwith, 2010; Sutherland, Benson, Adelman, \& McCleskey, 2001; Waldmann, Bassilana, et al., 1997; Yang and Palmer, 2014). Therefore, their activation is expected to depolarize the neurons thus, increasing neuronal excitability. Single channel conductance of ASICs varies in a range of 7 to $11 \mathrm{pS}$ depending on the subunit composition and the concentration of divalent cations (Immke and McCleskey, 2003; Paukert et al., 2004; Yang and Palmer, 2014).

While most ASICs are impermeable to $\mathrm{Ca}^{2+}$, the ASIC-1a subunit forms $\mathrm{Ca}^{2+}$-permeable heteromeric channels with ASIC-2b, and also $\mathrm{Ca}^{2+}$-permeable homomeric channels (Z. G. Xiong et al., 2004; Yermolaieva, Leonard, Schnizler, Abboud, \& Welsh, 2004 ; Lingueglia et al., 1997 ; Waldmann, Bassilana, et al., 1997; Waldmann, Champigny, et al., 1997 ; L. J. Wu et al., 2004). Reports on the permeability ratio $\mathrm{PNa}^{+} / \mathrm{PCa}^{+}$for ASIC1a are conflicting, since a large variability ranging from 2.5 to 18.5 has been reported (Bassler et al., 2001; Chu et al., 2002;; Samways, Harkins, \& Egan, 2009; Sherwood, Lee, Gormley, and Askwith,2011; Zhang and Canessa, 2002)-However, according to recent reports on the role of ASICs in synaptic plasticity and neurodegeneration, $\mathrm{Ca}^{2+}$ influx through ASICs is more relevant than previously considered (Grunder and Pusch, 2015; Wemmie et al., 2013). The tight control of proton affinity observed in the different ASICs seems to be the result of a highly cooperative gating mechanism. In addition, the ubiquity of potential ligand binding sites, suggests that there are several binding sites located in the external part of the channel (Grunder and Pusch, 2015). Gating of ASICs occurs on a millisecond time scale (Hesselager et al., 2004) and the mechanism involves three conformational states: resting, open and desensitized. The first occurring at a high $\mathrm{pH}$ and the other two states, at a low $\mathrm{pH}$.

When activated with a long pulse of acidic $\mathrm{pH}, \mathrm{ASIC}$ currents show a peak current followed by a complete or partial desensitization depending on their subunit composition (Hesselager et al., 2004). However, using recombinant ASIC1a homomers, ASIC1a/2a heteromers and native ASICs from sensory neurons, MacLean and Jayaraman (2016) have shown no desensitization of ASIC currents during high-frequency short-stimulus trains ( $1 \mathrm{~ms}$ acidification stimuli, switching from pH 8.0 to 5.0 ) as a result of an extremely fast deactivation of ASICs. This property of ASICs contrasts with most other deactivation properties of neurotransmitter-gated ion channels.

This article is protected by copyright. All rights reserved. 
The combination of unusual fast deactivation with slow desensitization enables recombinant ASIC1a homomers and ASIC1a/2a heteromers to follow trains of brief acid stimuli at high frequencies (MacLean and Jayaraman, 2016). These biophysical properties put ASIC channels in a position that favors sustained postsynaptic responses when other receptors, like glutamate, desensitize. In fact, during high frequency stimulation (HFS) at immature calyx of Held synapses, the role of ASIC currents in the total postsynaptic current during steady state depression increases from a small percentage, at the beginning of the train, to up to $10 \%$, suggesting that ASIC currents are more relevant in the young synapse, in which glutamate receptors become desensitized (GonzálezInchauspe et al. submitted). Thus, in conditions of high frequency communication like the one described at the calyx of Held, ASICs currents might be important to maintain synaptic transmission fidelity.

In a more recent work, MacLean and Jayaraman (2017), have shown that the deactivation kinetics of ASICla channels is highly dependent on the $\mathrm{pH}$, spanning nearly three orders of magnitude from extremely fast $(<1 \mathrm{~ms})$ at $\mathrm{pH} 8$ to very slow $(>300 \mathrm{~ms})$ at $\mathrm{pH}$. This channel behavior is compatible with a strong cooperativity in proton binding as evidenced by kinetic simulation and channel mutagenesis (MacLean and Jayaraman, 2017). Interestingly, the agonist-dependent deactivation could be the mechanism that shapes the time course of the postsynaptic current to brief-duration, small-amplitude acidic stimulation. Acidification will prolong, and alkalinization will shorten the post synaptic currents, making ASIC1a a more physiologically relevant mediator of charge transfer.

\section{MODULATION OF ASICS}

Since the discovery of ASICS and the recognition of their participation in a wide range of physiological and pathological processes, many endogenous and exogenous ligands have been identified (for an extensive review, see Osmakov, Andreev, \& Kozlov, 2014; Rash, 2017). Ligands can directly activate acid-sensitive channels, potentiating or inhibiting proton-induced currents through the channels. These molecules have a different chemical nature and interact, not always selectively, with ASICs. In this review we will focus on exogenous and endogenous ASIC1a, 2a and $2 b$ ligands, since these may modulate fast synaptic transmission at the CNS.

Exogenous ligands.

Clinically used diuretic amiloride (Korkushko and Kryshtal, 1984), was the first pharmacological tool used to study ASICs. Amiloride and its derivative benzamil have essentially no selectivity, inhibiting all ASIC homomeric channels with $\mathrm{IC}_{50}$ values in the 10-30 $\mu \mathrm{M}$ range. It acts as a pore blocker with the binding site at the bottom of the extracellular vestibule, which is the entry for ions to cross the membrane (Champigny, Voilley, Waldmann, \& Lazdunski, 1998; Baconguis, Bohlen, Goehring, Julius, \& Gouaux, 2014).

This article is protected by copyright. All rights reserved. 
Nonsteroidal anti-inflammatory drugs inhibit the activity of ASICs at concentrations relevant to their analgesic doses. Ibuprofen and flurbiprofen, for example, inhibit ASIC1a containing channels with an IC50 value of $350 \mu \mathrm{M}$. The proposed mechanism of action of the nonsteroidal anti-inflammatory drugs is that of allosteric inhibition of the channels by slowing the recovery after inactivation (Dorofeeva, Barygin, Staruschenko, Bolshakov, \& Magazanik, 2008; Lynagh, Romero-Rojo, Lund \& Pless,2017). Other drugs like Aspirin and salicylate inhibit ASIC3 containing channels (Voilley, 2004). In DRG neurons, aminoglycosides like streptomycin and neomycin, at a concentration of $30 \mu \mathrm{M}$, reversibly reduce ASIC current amplitudes and slow down the desensitization process (Garza, LopezRamirez, Vega, and Soto, 2010).

Diarylamidines, including 4,6-diamidine-2-phenylindole, diminazene, hydroxystilbamidine, and pentamidine are widely used to treat diseases caused by protozoa. They inhibit currents generated by ASIC receptors in hippocampal neurons with IC 50 values from 0.3 to $40 \mu \mathrm{M}$ (Chen et al., 2010). Inhibition of ASIC1a by diminazene involves both, allosteric modulation in the lower palm domain, and blocking of ion flow through the conduction pathway (Krauson, Rooney, and Carattino, 2018).

Hydrophobic monoamines like memantine are a recently described class of modulators, including endogenous amines (histamine) and pharmacological agents. These compounds potentiate and inhibit ASICs depending on their specific structure and on the subunit composition of the target channel. The action of monoamines also depends on the protocol applied, membrane voltage, conditioning and activating $\mathrm{pH}$, suggesting complex mechanism(s) of the ligand-receptor interaction (Shteinikov, Barygin, Gmiro, \& Tikhonov, 2019; Shteinikov, Tikhonova, Korkosh, \& Tikhonov, 2018).

Polypeptide modulators. Natural venoms are a well-established source of biologically active compounds (Osmakov et al., 2014). A series of polypeptides capable of modulating the activity of ASICs have been found in animal venoms. The first highly selective and potent pharmacological tool to study ASICs, named Psalmotoxin 1 (PcTx1), came from a tarantula venom peptide. PcTx1 is a small polypeptide consisting of 40 amino acids isolated from the spider Psalmopoeus cambridgei. It is a highly selective, high-affinity (IC50 $<1 \mathrm{nM}$ ) and potent inhibitor of homomeric ASIC1a in various cellular expression systems (Escoubas, Diochot, \& Corzo, 2000). The spatial structure of PcTx1 has been described as a compact central core stabilized by three disulfide bonds (Vassilevski, Kozlov, \& Grishin, 2009). Binding occurs at pH 7.4 with the channel existing in the closed state. This process is reversible. The effect of the toxin is exerted through its binding to the acidic pocket interacting with the thumb domain of the channel and a positive charged cluster of amino acids. This binding increases the affinity of ASIC 1 a for $\mathrm{H}^{+}$leading to desensitization of the channel. An interesting fact is that at $\mathrm{pH}$ values above 7.4, application of PcTx1 can lead to the activation of ASIC1a (Chen, 
Kalbacher, \& Grunder, 2005). It should also be noted that PcTx1 has a potentiating effect on ASIC1b (Chen, Kalbacher, \& Grunder, 2006).

Recent studies using heteromeric ASIC1a/2a channels have demonstrated a dual action of PcTX1 (Y. Liu, Hagan, \& Schoellerman, 2018). Potent inhibition occurs only at a pH that begins to desensitize the channel $(\mathrm{pH}$ 7.0). By contrast, strong potentiation can occur at physiological pH. PcTx1 potentiates ASIC1a/2a by increasing the apparent affinity of channel activation for protons. As such, potentiation is strongest at moderate $\mathrm{pH}$, diminishing with increasing proton concentrations. $\pi$-TRTX- (Hm3a) is a 37-amino acid peptide isolated from Togo starburst tarantula (Heteroscodra maculata) venom with five amino acid substitutions compared to PcTx1. Hm3a inhibits ASIC1a in a $\mathrm{pH}$ dependent way with an $\mathrm{IC}_{50}$ of 1-2 $\mathrm{nM}$, and potentiates $\mathrm{ASIC} 1 \mathrm{~b}$ with an $\mathrm{EC}_{50}$ of $46.5 \mathrm{nM}$, like PcTx1. Despite its high sequence similarity with PcTx1, Hm3a showed higher levels of stability over $48 \mathrm{hrs}$. Overall, Hm3a represents a potent, highly stable tool for long term in vitro and in vivo experiments (Er, Cristofori-Armstrong, Escoubas, and Rash, 2017).

The polypeptide MitTx was found in the venom of the coral snake. MitTx consists of two components, MitTx- $\alpha$ and MitTx- $\beta$, which are non-covalently associated with each other. Binding regions of MitTx- $\beta$ overlaps with that for PcTx1. MitTx activates all functional subtypes of ASICs at neutral pH. MitTx shows a strongest activity towards ASIC1a and ASIC1b subtypes (EC50 $=10$ and 23 $\mathrm{nM}$, respectively) but also blocks ASIC2a and ASIC3 at micromolar concentrations (Bohlen et al., 2011).

Mambalgin-1 and mambalgin-2 (Ma-1 and Ma-2), were isolated from the venom of the snake Dendroaspis polylepis polylepis. Mambalgin consists of a 57 amino acid structure with a tight central area stabilized by four disulfide bonds and three extended loops forming two $\beta$-layers (Kini and Doley, 2010). Such folding is named "three-finger toxins", typical for many well-known snake neurotoxin venoms. Mambalgins reversibly inhibit recombinant homomeric ASIC1a, heteromeric $A S I C 1 a / 2 a$ and $A S I C 1 a / 2 b$, as well as ASIC1b and ASIC1a/1b channels with IC50 values ranging from 55 to 192 nM (Diochot et al., 2016). Mambalgins bind near the AcP region and overlap the PcTx1 binding site (Schroeder et al., 2014).

Three polypeptides from different species of sea anemone named APETx2, Hcr 1b-1 and Ugr 9-1 were found to have specific inhibitory activity on ASIC3 (Kozlov et al., 2012). But more recently, new peptides were isolated from sea anemone Heteractis crispa named Hcr 1b-2, -3, -4 (Kalina et al., 2018). Electrophysiological experiments on homomeric ASIC channels expressed in Xenopus laevis oocytes establish that these peptides are the first inhibitors of ASIC1a derived from sea anemone venom. The major peptide, $\mathrm{Hcr} 1 \mathrm{~b}-2$, inhibited both ASIC1a with IC $\mathrm{C}_{50}$ of $4.8 \mu \mathrm{M}$ and ASIC3 with IC $\mathrm{I}_{50}$ of $16 \mu \mathrm{M}$.

This article is protected by copyright. All rights reserved. 
A-317567 is a small molecule, nonselective blocker of ASICs. In DRG neurons of rats, this molecule

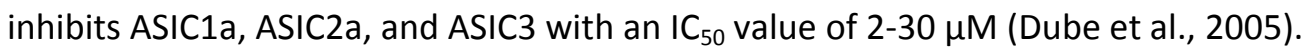

Aminopyridine (4-AP) is a well-known and nonselective, voltage-gated potassium channel blocker. Boiko et al (Boiko, Kucher, Eaton, \& Stockand, 2013) recently found that this molecule can also completely inhibit ASIC1a, 1b and 2a while having little effect on ASIC3.

A novel ASIC1a specific blocker was designed by molecular modeling by Krishtal group. The compound 2-oxo-2H-chromene-3-carboxamidine derivative 5b, inhibits ASIC1a currents with an apparent $\mathrm{IC}_{50}$ of $27 \mathrm{nM}$ when measured at $\mathrm{pH}$ 6.7. Acidification to 5.0 decreases the inhibition efficacy up to 3 orders of magnitude. The $5 \mathrm{~b}$ molecule not only shifts $\mathrm{pH}$ dependence of ASIC1a activation, but also inhibits its maximal evoked response (Buta et al., 2015).

The actions of a series of antidepressant on recombinant ASIC1a and ASIC2a, and on native ASICs in rat brain neurons was studied by Nikolaev et al. (2018). Most of the tested compounds prevent steady-state ASIC1a desensitization evoked by conditioning acidification to $\mathrm{pH}$ 7.1. Amitriptyline also potentiates ASIC1a responses evoked by $\mathrm{pH}$ drops, suggesting a twofold effect: it shifts activation to less acidic values, while also shifting steady-state desensitization to more acidic values. Other antidepressants like chlorpromazine, desipramine, fluoxetine, atomoxetine and amitriptyline potentiate ASIC2a response, while tianeptine causes strong inhibition on ASIC2a.

Other non-specific or partially studied compounds inhibitors of ASICs are the local anesthetics, tetracaine and propofol (Lei et al., 2014; Leng and Xiong, 2013; Wu et al., 2011). The alkaloid used in Chinese medicine, sinomenine, is a potent blocker of ASIC 1a (IC $501 \mu \mathrm{M}$; Wu et al., 2011). A drug named NS383 identified using a fluorescence-based screening against human ASIC1a (Munro et al., 2016), has been shown to have a potent and selective ASIC1a inhibitory activity (IC $50.44 \mu \mathrm{M}$ ) with mild effect on ASIC3 and no effect on ASIC2a. PPC-5650 a novel drug candidate from the biotech company called Painceptor, is claimed to be a selective ASIC1a inhibitor (IC $500 \mathrm{nM})$. It was tested in a small human trial for analgesic activity (UV sunburn model), and showed promising effects (Dube, Elagoz, \& Mangat, 2009).

Endogenous ligands.

While ASIC channels are mainly activated by protons, the size and time course of the currents could substantially change due to the modulatory effects of endogenous ligands in physiological and pathological conditions. Importantly, identification of endogenous ligands could be a first step towards the design of new pharmacological tools.

Arachidonic acid $(\mathrm{AA})$ is a polyunsaturated fatty acid present in phospholipids of all cell membranes. AA functions as a secondary messenger, but it also plays an important role in conditions such as inflammation and ischemic brain injury (Farooqui and Horrocks, 2006). AA (5-10 $\mu$ M) was first 
observed to enhance ASIC signaling in rat cerebellar Purkinje cells (Allen and Attwell, 2002). AA is a nonselective enhancer of ASIC1a, ASIC2a, and ASIC3 (Smith, Cadiou, and McNaughton, 2007) by shifting the $\mathrm{pH}$ activation curve towards alkaline $\mathrm{pH}$ (Deval et al., 2008).

Neuropeptides RF-amide (named after their C-terminal Arg-Phe-amide motif) and similar peptides related to inflammatory processes are nonselective potentiators of ASICs (EC 50 10-50 $\mu \mathrm{M}$ ) (Askwith et al., 2000). RF-amides interact with the ASIC channels extracellular domain, which results in an increase in the current amplitude and deceleration of desensitization of ASIC1 and ASIC3 (but not ASIC2a) due to a decrease of proton sensitivity for sites responsible for steady-state desensitization (Askwith et al., 2000; Ostrovskaya, Moroz, \& Krishtal, 2004; Sherwood and Askwith, 2008).

Dynorphins are a class of endogenous opioid neuropeptides abundantly represented in the CNS. Although unrelated to the RFamides, they share the ability to enhance ASIC currents ( $\left.E_{50} \sim 30 \mu \mathrm{M}\right)$ and they can directly activate channels related to the DEG/ENa family. They are involved in various physiological processes including analgesia and neuroendocrine signal transmission. Unlike the RFamides, the effects of dynorphins appear to be restricted to ASIC1a and ASIC1b and may share their binding site with PcTx1 (Sherwood et al., 2009; Vick and Askwith, 2015). More recently, an unbiased screen of 109 short neuropeptides (< 20 amino acids) on five homomeric ASICS (ASIC1a, ASIC1b, ASIC3, ASIC4 and BASIC) revealed that they exert no direct agonist action on any ASIC, but three of them were modulators. In particular, the mammalian neuropeptide, dynorphin A, is already known to increase ASIC1a currents of partially desensitized channels (Vyvers, Schmidt, Wiemuth, \& Grunder, 2018). Thus, dynorphin might exacerbate brain damage in pathological conditions associated with ischemia.

Interleukin 6 (IL-6) Cytokines are essential modulators of the immune response; and IL-6 is one of the main neuroinflammatory cytokines in the CNS. The effect of IL- 6 was investigated in dissociated mouse hippocampal cultures after 8-12 days in vitro. After incubation for 30 minutes (10ng/ml), IL-6 determined the redistribution of ASIC1 channels to the plasma membrane, which correlated with an increase in ASIC1 currents amplitude suggesting that IL-6 may potentiate ASIC currents by increasing the channel density at the cell membrane (Weissmann et al., 2017).

ASIC channels are modulated by divalent cations, especially $\mathrm{Ca}^{2+}$, which play an important role in the regulation of various voltage-dependent and ligand-gated ion channels. (Babini, Paukert, Geisler, \& Grunder, 2002) show that extracellular divalent cations $\left(\mathrm{Ca}^{2+}\right.$ and $\left.\mathrm{Mg}^{2+}\right)$ shift the steady state inactivation of ASIC1a and $1 \mathrm{~b}$ to more acidic values. Immke and McCleskey, (2003) have proposed that the bound $\mathrm{Ca}^{2+}$ blocks permeation, and that channel conducts when multiple $\mathrm{H}^{+}$ions relieve this block. However, further studies on ASIC1a revealed that they have two $\mathrm{Ca}^{2+}$-binding sites: one serves

This article is protected by copyright. All rights reserved. 
as a pore block; and the other mediates Ca-dependent regulation of activation by protons (Paukert et al., 2004; P. Zhang, Sigworth, and Canessa, 2006).

$\mathrm{Zn}^{2+}$ is a divalent cation concentrated in nerve terminals in various brain regions and is released into the extracellular space during excitatory stimulation. Zinc ions play an important role in the regulation of ASIC channels. In neurons acutely dissociated from the rat hippocampal CA1, ASICS currents mediated through a mixture of homomeric ASIC1a and heteromeric ASIC1a+2a were potentiated by low $\mathrm{Ca}^{2+}$ or high $\mathrm{Zn}^{2+}(\mathrm{Gao}, \mathrm{Wu}, \mathrm{Xu}$, and $\mathrm{Xu}, 2004)$. However, it was shown that $\mathrm{Zn}^{2+}$ in nanomolar concentrations inhibits currents generated by homomeric ASIC1a and heteromeric ASIC1a/2a channels reducing the affinity of ASIC1a for protons. In contrast, at concentrations greater than $100 \mu \mathrm{M}, \mathrm{Zn}^{2+}$ interacts also with the low-affinity binding site on the ASIC2a subunit, which increases affinity for protons and potentiates activity of ASIC2a-containing channels (Baron, Schaefer, Lingueglia, Champigny, \& Lazdunski, 2001).

ASICs are modulated by $\mathrm{Cu}^{2+}$ as shown in cell cultures of hypothalamus. Copper dose-dependently reduces the amplitude of ASIC currents as well as slows desensitization. $\mathrm{Cu}^{2+}$ can be regarded as an endogenous modulator that reduces the increased neuronal excitability mediated by ASICs (Wang, $Y u, \& X u, 2007)$.

Recent studies have shown that certain endogenous ligands associated with ischemia, such as spermine and lactate (Allen and Attwell, 2002; Immke and McCleskey, 2001) can enhance ASIC-1a currents. Spermine, one of the endogenous polyamines synthesized by mammals from the diamine putrescine, interacts with acidic residues of different nature. Therefore, multiple actions have been suggested for these polycations, including modulation of the activity of ionic channels (Guerra, Rubin, \& Mello, 2016). Spermine exerts a potentiating effect on the activity of ASIC1a and ASIC1b channels (Babini et al., 2002). Extracellular spermine (250-500 $\mu \mathrm{M}$ ) enhances ASIC1a and ASIC1b currents by decreasing the $\mathrm{pH}$ sensitivity of channel steady-state desensitization (Babini et al., 2002) (Duan et al., 2011). Spermine exacerbates damage of neurons during ischemia through increasing ASIC1a sensitivity to extracellular medium acidification inducing depolarization of neurons and overloading of the cytoplasm with $\mathrm{Ca}^{2+}$ (Duan et al., 2011).

Intense activity and hypoxia are factors that cause an increase in lactate production and concentration in the brain ((Vannucci and Hagberg, 2004). The role of extracellular lactate in enhancing the activity of ASICs through chelation of extracellular calcium is known to involve modulation of ASIC-1a (Immke and McCleskey, 2001). Calcium ions block ASIC-1a channels as a result of competition between $\mathrm{Ca}^{2+}$ and $\mathrm{H}^{+}$at the activation site (Immke and McCleskey, 2003; Paukert et al., 2004), while lactate binds and diminishes extracellular free $\mathrm{Ca}^{2+}$, thereby allowing the channel to open at lower $\mathrm{H}^{+}$concentrations.

This article is protected by copyright. All rights reserved. 
Histamine is a neurotransmitter synthesized by neurons in the tuberomammillary nucleus of the posterior hypothalamus (Sherin, Elmquist, Torrealba, \& Saper, 1998). Histamine-containing nerve fibers project to many structures in the brain (Panula and Nuutinen, 2013), and histaminergic circuits regulate numerous physiological functions and behaviors, including sleep-wake activities, circadian and feeding rhythms, learning, and memory (for review see Kohler, da Silva, Benetti, and Bonini, 2011; Vitrac and Benoit-Marand, 2017). It has recently been reported that synthetic hydrophobic monoamines potentiate or inhibit ASIC currents in a subunit-specific manner (Shteinikov et al., 2019; Shteinikov, Korosteleva, Tikhonova, Potapieva, \& Tikhonov, 2017). Histamine (30 $\mu \mathrm{M})$, was found to selectively potentiate ASIC1a homomers expressed in heterologous systems. Its action is particularly pronounced at minor acidifications, which cause small responses (Nagaeva et al., 2016). The potentiation effect of histamine on ASIC1a currents in ex vivo stem brain slices was recently demonstrated by our group (Fig 1) (González Inchauspe C., Gobetto N. \& Uchitel O.D., 2019).

Recent studies have shown that ASIC1a is involved in stress response. It has been shown that corticosterone, a stress-induced hormone applied extracellularly (1-10 $\mu \mathrm{M})$, increases ASIC currents. In contrast, intracellular application has no effect. Likewise, the application of corticosterone further increases ASIC currents in the presence of agonists of protein kinase $C$ (PKC), a phenomenon inhibited by PKC antagonists. This indicates that the increase is caused by the activation of corticoid receptors on the cellular membrane of the neurons and may involve a PKC-dependent mechanism (Xiong et al., 2013). A more recent work by the same group used a combination of electrophysiological and behavioral approaches to explore the effects of acute stress on ASICs. Again, corticosterone induced by acute stress caused a potentiation of ASICs currents via glucocorticoid receptors, (and not mineralocorticoid receptors), by activating PKC signaling pathway, which leads to potentiated learning and memory (Ye et al., 2018).

The activities of ASICS in CNS neurons are tightly regulated by the redox state of the channels and the modulation is ASIC1a subunit dependent. In cultured mouse cortical neurons, application of reducing agents dramatically potentiated, whereas oxidizing agents inhibited ASIC currents. In CHO cells, redox-modifying agents only affected the current mediated by homomeric ASIC1a, but not homomeric ASIC1b, ASIC2a, or ASIC3 (Chu, Close, Saugstad, \& Xiong, 2006).

Nitric oxide (NO) potentiates the activity of ASICs due to an alkaline shift of the $\mathrm{pH}$ dependent activation (Cadiou et al., 2007). The NO donor S-nitroso-N-acetylpenicillamine potentiates protongated currents in DRG neurons and proton-gated currents in $\mathrm{CHO}$ cells expressing each of the acidsensitive ASIC subunits. Furthermore, in excised patches from $\mathrm{CHO}$ cells expressing ASIC2a, the potentiation could be reversed by externally applied reducing agents. NO, therefore, has a direct 
external effect on the ASIC ion channel, probably through oxidization of cysteine residues (Cadiou et al., 2007).

\section{PROTONS AS NEUROTRANSMITTERS}

In the nervous system, transmission of information occurs primarily through chemical signaling by small molecules packaged in synaptic vesicles (De Robertis, Rodriguez De Lores Arnaiz, \& Pellegrino De Iraldi, 1962) and released in quanta (Katz, 2003). Many molecules have been identified in the past as chemical neurotransmitters according to the following criteria: 1) A chemical neurotransmitter must be present in the presynaptic cell; 2 ) It must be released upon stimulation; 3) It must have a receptor in the postsynaptic cell; 4) Exogenous application of the putative neurotransmitter should mimic the endogenous response; 5) Blocking or eliminating the receptor must block the putative neurotransmitter action; 6) A mechanism to limit the action of the transmitter should exist.

The detection of the acute $\mathrm{pH}$ sensitivities of voltage-gated calcium channels (lijima, Ciani, \& Hagiwara, 1986), ligand-gated NMDA receptors (Traynelis and Cull-Candy, 1990), GABA receptors (Kaila, 1994), and the discovery of proton-gated ASICs (Waldmann and Lazdunski, 1998), (Krishtal and Pidoplichko, 1981), suggests that $\mathrm{pH}$ regulation plays a crucial role in synaptic signaling. Nevertheless, the role of protons as neurotransmitters being released from the presynaptic structure and capable of activating a specific receptor in the postsynaptic neuron or muscle cell has been accepted only a few years ago.

Protons have properties that make them well suited to play a role in neurotransmission. Protons have a very high rate constant of diffusion (for review on the Grotthuss effect see Cukierman, 2006), and fast changes in proton concentration can be achieved in physiological conditions driven by channels, ion exchangers or vesicle exocytosis. Protons can affect the structure and function of most proteins. Studies using knock-out mouse models of proton receptor ion channels like ASICs have shown their participation in a broad range of physiological functions, including learning and memory (Wemmie et al., 2002; Zha, Wemmie, Green, \& Welsh, 2006)

The first indication of protons acting as transmitters was found in the C. elegans defecation motor program, where the space between the intestine and the muscle is acidified just prior to muscle contraction (Beg, Ernstrom, Nix, Davis, \& Jorgensen, 2008). A putative $\mathrm{Na}^{+} / \mathrm{H}^{+}$ion exchanger is expressed in the intestine and genes encoding for subunits to a proton gated cation channel halfmaximally activated at a $\mathrm{pH}$ of 6.8 are expressed in the faced muscle fiber. Therefore, Beg et al., (2008) have proposed that $\mathrm{H}^{+}$acts as transmitters and they postulated that $\mathrm{Na}^{+} / \mathrm{H}^{+}$ion exchanges or synaptic vesicle protons could be the source of protons as neurotransmitters in C. elegans CNS.

This article is protected by copyright. All rights reserved. 
Studying the synapse formed by the inner ear type I vestibular hair cells and the postsynaptic calyx nerve terminals, Highstein et al., (2014) have presented evidences that protons act as a non-quantal neurotransmitter. Stimulus-evoked extrusion of protons revealed by $\mathrm{pH}$ imaging demonstrates acidification, within the confined chalice-shaped synaptic cleft, leading to modulation of postsynaptic cationic conductance. However, whether the non-quantal postsynaptic current was directly gated by protons or by second messenger is still to be investigated.

The possibility that protons might be neurotransmitters triggering postsynaptic ASIC currents was investigated in hippocampal neurons with negative results. This was unexpected because previous studies of extracellular field potential recordings in hippocampal brain slices suggested impaired hippocampal long-term potentiation (LTP) in ASIC1a ${ }^{-/-}$mice (Wemmie et al., 2002). Another study using micro-island cultures of hippocampal neurons suggested that the probability of neurotransmitter release increased in $\mathrm{ASICla}^{-/-}$mice (J. H. Cho and Askwith, 2008).

Du et al., (2014) tested the hypothesis that protons are neurotransmitters and that ASICs are the receptors at lateral amygdala brain slices. They chose this preparation because ASICs are abundantly expressed there, and amygdala-dependent fear-related behavior depends on a $\mathrm{pH}$ reduction and is impaired in ASIC1a ${ }^{-/-}$mice (Ziemann et al., 2009; Wemmie et al., 2003; Price et al., 2014). Du et al., (2014) recorded excitatory postsynaptic glutamatergic currents (EPSCs) in wild-type (WT) and $\mathrm{ASICla}^{-/-}$mice. After blocking glutamate receptor (GluR), a small component of the EPSC, sensitive to the non-specific ASIC blocker amiloride, remained in neurons from WT but not from ASIC1a ${ }^{-/-}$ mice. PcTX1, a specific blocker of homomeric ASIC1a channels has little effect on GluR-independent EPSCs in WT amygdala slices, but inhibited the current in neurons from $\mathrm{ASIC2}^{-/-}$brain slices, consistent with the idea that the majority of ASIC currents arising from WT amygdala are generated by ASIC1/2 heteromeric channels and those blocked by PcTX1 resulted from the activation of homomeric ASIC1a.

According to the hypothesis that postsynaptic ASICs are activated by protons, Du et. al., (2014) were able to record stimulus dependent acidification with a $\mathrm{pH}$ sensitive phluorin inserted in the postsynaptic membrane. Furthermore, they observed an increase in the amplitude of the signal when the buffer capacity of the bath solution was diminished, as expected from proton activated ASIC currents. The ASIC currents generated by cortical stimulation were eliminated by treating the slices with $\mathrm{Ca}^{2+}$ channel blockers consistent with proton release from synaptic vesicles, as a source for the reduced $\mathrm{pH}$. However, it is possible that other transport processes are involved in the acidification (Beg et al., 2008; for review see Sinning and Hubner, 2013).

ASICs are abundant in the nucleus accumbens (NAC), a region known for its role in addiction (Scofield et al., 2016). Investigating the role for ASICs in the underlying mechanisms of addiction related 
behavior, Kreple et al., (2014) identified a postsynaptic current that was mediated by ASIC1a and ASIC2. ASIC mediated currents were revealed after pharmacologically blocking AMPA, NMDA and GABAA receptors. They were nearly eliminated in the Asic1 $a^{-/-}$mice and were rescued by virusmediated ASIC1a expression. They were blocked by amiloride, but not by PcTx1, unless ASIC2a and ASIC2b subunits were genetically eliminated, indicating that ASICs in the NAc of WT mice are mostly heteromeric channels. The amplitude was also sensitive to the $\mathrm{pH}$ buffer capacity of the extracellular solutions. Furthermore, ASIC mediated currents were affected by carbonic anhydrase IV (CA-IV), an enzyme that is critical for regulating extracellular pH buffering in the brain (Kreple et al., 2014). Carbonic anhydrase inhibition with acetazolamide and CA-IV disruption (Car4 ${ }^{-/-}$mice) increased the postsynaptic ASIC currents and acetazolamide no longer exerted its effects in the absence of ASIC1a and CA-IV. These ASIC currents, detected in the postsynaptic cell, occurred in the same time frame as postsynaptic glutamate receptor activation and their amplitudes remained a similar percentage (5\%) of the total EPSC suggesting that protons are co-released with glutamate from the presynaptic terminal.

ASIC channels are also expressed at the postsynaptic principal neurons of the calyx of Held-medial nucleus of the trapezoid body (MNTB) synapse of the auditory CNS (Fig 1 B). The calyx of Held-MNTB synapse provides a model system to analyze basic mechanisms of synaptic transmission due to the large size of the presynaptic terminal and the numerous release sites that can be activated simultaneously (for review see (Baydyuk, Xu, \& Wu, 2016; von Gersdorff and Borst, 2002; Borst and Soria van Hoeve, 2012). This particular property of a giant synapse allows the recording of signals that may be present in other synapses but not resolved due to their small amplitude. We (GonzalezInchauspe et al., 2017), have found that the presynaptic terminal of the brainstem calyx of Held synapse lacks ASIC channels while the MNTB neurons respond to acidification with a transient inward current sensitive to amiloride and to PcTx1(see also Lujan et al., 2019).We have also shown the absence of these currents in $\mathrm{ASICla}^{-/-}$mice suggesting that homomeric ASIC-1a mediate these currents in MNTB neurons. Furthermore, we have detected ASIC1a-mediated currents during synaptic transmission after blocking AMPA and NMDA glutamate receptors, suggesting that an acidification of the synaptic cleft due to the co-release of neurotransmitter and $\mathrm{H}^{+}$from synaptic vesicles is capable of activating ASIC postsynaptic channels. These protonergic postsynaptic currents were very small compared to the glutamatergic currents (1-3\%), but clearly distinguished after elimination of glutamate mediated synaptic currents (Fig 1A). They were strongly diminished in amplitude by amiloride and PcTx1 and by an extracellular media with increased buffer capacity; and they were also desensitized by low pH extracellular media (González-Inchauspe et al., 2017. Furthermore, ASIC1a synaptic currents were increased by inhibition of carbonic anhydrase with 
acetazolamide as expected for synaptic currents activated by evoked released protons (González Inchauspe et al., 2019). In a recent work from our group, we were able to show that the ASIC1a dependent synaptic currents at the calyx of Held were strongly potentiated by histamine (Fig $1 \mathrm{~A}$ ), lactate and spermine (González Inchauspe et al., 2019).The potentiating effect of each one added to the previous one with no occlusion. This is a remarkable modulation capable of increasing the power of the proton mediated currents to significant levels, enough to depolarize the postsynaptic cell and elicit an action potential. Furthermore, during the steady state phase of the short-term depression undergone in HFS, histamine enhanced EPSC amplitudes by $10 \%$. As a result of such potentiation, the total participation of ASIC current on EPSC amplitude during the steady state phase of the HFS is over $20 \%$ as shown by its inhibition when the buffer capacity of the media was increased. Therefore, enhanced postsynaptic ASIC currents contribute to maintain the fidelity of HFS synaptic transmission (González Inchauspe et al., 2019). This could be highly significant in conditions in which postsynaptic AMPA receptors become desensitized, as happens early in development (Koike-Tani, Kanda, Saitoh, Yamashita, \& Takahashi, 2008)

A significant characteristic of homomeric ASIC-1a channels is their permeability to $\mathrm{Ca}^{2+}$ (Yermolaieva et al., 2004; Xiong et al., 2004; Xiong, Chu, \& Simon, 2006). Activation of ASIC-1a channels in MNTB neurons by exogenous $\mathrm{H}^{+}$induces an increase in intracellular $\mathrm{Ca}^{2+}$. Furthermore, the activation of postsynaptic ASIC-1a synaptic currents during HFS of the presynaptic nerve terminal leads to a PcTx1-sensitive increase in intracellular $\mathrm{Ca}^{2+}$ in MNTB neurons, which is independent of glutamate receptors and is absent in neurons from $\mathrm{ASIC}^{-a^{-/}}$mice. These results strongly support the hypothesis of protons as neurotransmitters and demonstrate that presynaptic released protons contribute to synaptic transmission by activating ASIC-1a at the calyx of Held-MNTB.

Interestingly, ASIC1a synaptic currents, but not the extrasynaptic currents, diminished their amplitude and disappeared in older mice (over 30 days) contrasting with the ASIC synaptic currents found in the amygdala (Du et al., 2014), the NAc (Kreple et al., 2014,) and the anterior cingulate cortex from adult mice (Li et al. 2018).

\section{ASIC CHANNELS AND SYNAPTIC PLASTICITY}

It has been proposed that proton gated currents released during synaptic transmission play a role in the physiology and plasticity of synaptic transmission (Krishtal et al., 1987; Waldmann, Champigny, et al., 1997). It is now well established that in some synapses, protons activate an inward current at postsynaptic cells. However, the amplitude of the proton-activated EPSCs is small, 1-5\%, compared to that generated by glutamate gating AMPA receptors (Du et al., 2014; Highstein, Holstein, Mann, and Rabbitt, 2014; Kreple et al., 2014; González-Inchauspe et al., 2017; Lujan et al., 2019). Despite the small amplitude and the inhibitory effect of protons on NMDA receptors, ASIC activation allows

This article is protected by copyright. All rights reserved. 
$\mathrm{Na}^{+}$influx, post synaptic depolarization and the relief of blockade of NMDA receptors by $\mathrm{Mg}^{2+}$, thus, facilitating $\mathrm{Ca}^{2+}$ influx through them. Furthermore, ASIC1a are $\mathrm{Ca}^{2+}$ permeable channels and HFS of the presynaptic nerve terminal at the Calyx of Held MNTB synapse triggers an ASIC1a dependent postsynaptic Ca ${ }^{2+}$ influx (González-Inchauspe et al., 2017). Thus, ASIC synaptic currents could be important for the generation of synaptic plastic changes.

It has been suggested that ASIC1a activated during synaptic transmission modulate short term plasticity. Using micro island cultures of hippocampal neurons from wild-type and ASIC knockout mice, J. $\mathrm{H}$ et al (Cho and Askwith, 2007) found that paired-pulse ratios were reduced, and spontaneous miniature EPSCs occurred at a higher frequency in ASIC1 null mouse neurons compared with wild type. They concluded that the release probability was increased in the ASIC1a ablated neurons, indicating that ASIC1a can affect presynaptic mechanisms of synaptic transmission.

At the mouse neuromuscular junction, Urbano et al (Urbano et al., 2014) reported a decrease in the frequency of spontaneous release of acetylcholine due to extracellular local application of acid saline solutions, an effect not shown at the neuromuscular junctions of ASIC1a null mice. Furthermore, evoked release was increased by inhibiting ASIC1a with PcTx1 and Hepes $10 \mathrm{mM}$. In this experimental setting, the nerve terminal seems to be inhibited, while the activation of ASIC should have a depolarizing excitatory effect. Therefore, it is possible to predict a scenario where an inhibitory signal is released by a neighbor depolarized cell through ASIC activation. Indeed, preliminary results suggest that ASIC channels are located on Schwann cells known to release inhibitory modulators of vesicle recycling (Perissinotti and Uchitel, 2010).

At the calyx of Held, synaptic transmission during HFS reveals modulation of synaptic plasticity by ASIC activation. The lack of ASIC1a or their pharmacological inhibition during HFS results in a faster and stronger short-term depression (STD) with lower steady-state values of EPSC amplitudes at the end of the stimuli. In WT mice, PCTX1 mimics the effect on STD that was observed on ASIC1a ${ }^{-/-}$mice; and the same happened when STD was measured in a high-pH buffer capacity bath solution that prevented acidification and the subsequent ASIC activation. Therefore, presynaptically released protons modulate presynaptic neurotransmitter release through the activation of postsynaptic ASICs, indicating that, through an undisclosed pathway, ASIC activation increases probability of release or the size of the synaptic vesicle ready releasable pool (Gonzalez-Inchauspe et al., 2017).

Consistent with a role as postsynaptic proton receptors, ASICs regulate structural remodeling of synaptic sites. In hippocampal slices, acute or chronic overexpression of ASIC1a increases the density of dendritic spines (Zha et al., 2006). Furthermore, since ASIC2 and ASIC1a are associated in the brain, it has been proposed that through its interaction with PSD-95, ASIC2 facilitates ASIC1a localization and function in dendritic spines. Therefore, the two subunits might be working in 
concert to regulate neuronal function. (Zha et al., 2006; Zhang, Mao, Wang, \& Chu, 2009). On the contrary, deleting ASIC1a increases spine density in the NAC (Kreple et al., 2014). Differences on the effect of ASIC1a gene ablation were also observed on the ratio of AMPA/NMDA currents in hippocampal neurons in culture and NAc neurons (Cho and Askwith, 2008; Kreple et al., 2014). Thus, ASICs are important molecules to define the dendritic spine properties; however, the mechanism is not understood, and the precise effect depends on the system studied.

Further evidence of the role of ASICS on synaptic plasticity is provided by ASIC dependent long-term potentiation (LTP). This was first reported in the amygdala (Du et al., 2014), consistent with a previous report which shows an attenuation of LTP in ASIC1a null hippocampal slices (Wemmie et al., 2002). The loss of ASICs has no effect on LTD. The effect on LTP was questioned (P. Y. Wu et al., 2013), but more recent reports confirmed that genetic deletion or pharmacological blockade of ASIC1a greatly reduced the probability of LTP induction in hippocampal CA1 region (M. G. Liu et al., 2016). Similarly, inhibiting ASIC1a channels with 5b, a novel potent orthosteric antagonist of ASIC1a, prevents NMDAR-dependent LTP (Buta et al., 2015). Furthermore, levglevskyi et al., 2016 showed that inhibition of ASIC with $5 b$ leads to a strong increase in the frequency of spontaneous inhibitory postsynaptic currents and reduces epileptic discharges in a model of epilepsy suggesting that GABAergic neuronal activity may underlie the inhibitory effect exerted through ASIC channels.

In agreement with these findings, ASIC1a null mice displayed alterations in spatial learning and eyeblink conditioning (Wemmie et al., 2002), procedural motor learning (Ye et al., 2018) and Pavlovian reward conditioning (Ghobbeh et al., 2018) among others.

The effect of ASIC1a genetic ablation on synaptic plasticity changes has also been studied in several areas of the brain (Wemmie et al., 2003). The amygdala is an area that detects carbon dioxide and acidosis to elicit fear behavior. Strong ASIC expression was found in glutamatergic principal neurons and at the GABAergic neurons, at the output station of the amygdala circuitry (Chiang, Chien, Chen, Yanagawa, \& Lien, 2015). Notably, eliminating or inhibiting ASIC1a markedly reduced fear behavior; and restoring ASIC 1a expression via a viral vector rescued the CO2-induced fear deficit (Du et al., 2014). Analysis of synaptic plasticity revealed that the abundance of ASICs in postsynaptic neurons correlated with, and contributed to, LTP of glutamatergic synapses and fear-like behavior (Ziemann et al., 2009).

In the nucleus accumbens, a region of the brain that has an established role in regulating drugseeking behavior, ASICs are abundantly expressed and upregulated after removal of cocaine or amphetamine exposure (G. C. Zhang, Mao, Wang, \& Chu, 2009; Suman et al., 2010). ASIC synaptic currents elicited by stimulating inputs from the prefrontal cortex were described by (Kreple et al., 2014), (see above). Interestingly ASIC1a null mice have increased sensitivity to cocaine. In those 
animals, glutamate receptor function and subunit composition are different to what has been found in cocaine withdrawal animals, even though the ASIC 1a null mouse had never been exposed to cocaine. Restoring ASIC1a to the NAc via a viral vector produces the opposite effect and reduces cocaine conditioned place preference. Furthermore, overexpressing ASIC1a in the rat NAc via adenoassociated virus, alters the processes underlying extinction and cocaine-seeking behavior (Gutman et al., 2018), suggesting complex roles of ASIC1a in modulating synaptic plasticity and behavioral adaptation.

ASIC1a are abundant in the striatum (Jiang et al., 2009), which serves as the input nucleus of the basal ganglia and is critically involved in procedural learning and motor memory. (Packard and Knowlton, 2002; Ye et al., 2018) found that deletion of ASIC1a gene in mice led to increased dendritic spine density, impaired spine morphology and postsynaptic architecture, which were accompanied by decreased function of NMDA receptors at excitatory synapses. These changes were mediated by reduced activation of protein kinases. The ASIC1a null mice exhibited poor performance on multiple motor tasks, which was rescued by striatal-specific expression of either ASIC1a or CaMKII. These results revealed that ASIC1a promotes the excitatory synaptic function underlying striatum-related procedural learning and memory.

In contrast to the established role for ASIC1a in LTP, which promotes associative learning and memory in several brain areas, ASIC1a is a critical modulator of long-term depression (LTD) in the insular cortex and this function is important for the extinction of the acquired taste aversion memory. Furthermore, since the diminished LTD in ASIC1a null mice was restored by re-introduction of WT, but not the pore-dead mutant of ASIC1a in insular neurons, the ionic conductance of ASIC1a is crucial for its role in insular synaptic depression (W. G. Li et al., 2016).

\section{CONCLUSION}

It is well established that protons act as neurotransmitters and neuromodulators during synaptic transmission playing a significant role in the physiology and plasticity of many synapses. However, synaptic cleft $\mathrm{pH}$ waveforms have not been described and probably follow complex patterns, including an acid and alkaline shift with a time course dependent on the buffer capacity of the cleft. In ribbon type synapses, changes in $\mathrm{pH}$ affect presynaptic calcium channels and modulate transmitter release. In some glutamatergic synapses, protons generate a postsynaptic inward current dependent upon the activation of ASICs, trimeric cation selective ion channels activated by protons in the physiological range. The EPSCs triggered by $\mathrm{pH}$ changes are generated by $\mathrm{Na}^{+}$and $\mathrm{Ca}^{2+}$ currents through ASIC1a homomers and ASIC1a/2a heteromers and are subjected to physiological inhibition or potentiation by endogenous molecules. The ASICs currents exhibit activation and 
deactivation kinetics that allow following HFS that desensitize most of the ion channels activated by other neurotransmitters.

Given the unique biophysical properties and sensitivity to endogenous modulators, ASIC-mediated transmission emerges as a particularly powerful mechanism for encoding information and for activating Ca-dependent plasticity throughout the nervous system.

\section{References}

Allen, N. J., \& Attwell, D. (2002). Modulation of ASIC channels in rat cerebellar Purkinje neurons by ischaemia-related signals. J Physiol, 543(Pt 2), 521-529.

Alvarez de la Rosa D, Krueger SR, Kolar A, Shao D, Fitzsimonds RM, Canessa CM. (2003) Distribution, subcellular localization and ontogeny of ASIC1 in the mammalian central nervous system. J Physiol. 546(Pt 1):77-87.

Anderson, R. G., \& Orci, L. (1988). A view of acidic intracellular compartments. J Cell Biol, 106(3), 539-543.

Askwith, C. C., Cheng, C., Ikuma, M., Benson, C., Price, M. P., \& Welsh, M. J. (2000). Neuropeptide FF and FMRFamide potentiate acid-evoked currents from sensory neurons and proton-gated DEG/ENaC channels. Neuron, 26(1), 133-141.

Askwith, C. C., Wemmie, J. A., Price, M. P., Rokhlina, T., \& Welsh, M. J. (2004). Acid-sensing ion channel 2 (ASIC2) modulates ASIC1 H+-activated currents in hippocampal neurons. J Biol Chem, 279(18), 18296-18305. doi:10.1074/jbc.M312145200

Babini, E., Paukert, M., Geisler, H. S., \& Grunder, S. (2002). Alternative splicing and interaction with di- and polyvalent cations control the dynamic range of acid-sensing ion channel 1 (ASIC1). J Biol Chem, 277(44), 41597-41603. doi:10.1074/jbc.M205877200

Baconguis, I., Bohlen, C. J., Goehring, A., Julius, D., \& Gouaux, E. (2014). X-ray structure of acidsensing ion channel 1-snake toxin complex reveals open state of a $\mathrm{Na}(+)$-selective channel. Cell, 156(4), 717-729. doi: 10.1016/j.cell.2014.01.011

Baconguis, I., \& Gouaux, E. (2012). Structural plasticity and dynamic selectivity of acid-sensing ion channel-spider toxin complexes. Nature, 489(7416), 400-405. doi:10.1038/nature11375

Banke TG, Dravid SM, Traynelis SF. Protons trap NR1/NR2B NMDA receptors in a nonconducting state. J Neurosci. 2005 Jan 5;25(1):42-51.

Barnes, S., \& Bui, Q. (1991). Modulation of calcium-activated chloride current via pH-induced changes of calcium channel properties in cone photoreceptors. J Neurosci, 11(12), 4015-4023.

Barnes, S., Merchant, V., \& Mahmud, F. (1993). Modulation of transmission gain by protons at the photoreceptor output synapse. Proc Natl Acad Sci U S A, 90(21), 10081-10085. 
Baron, A., Deval, E., Salinas, M., Lingueglia, E., Voilley, N., \& Lazdunski, M. (2002). Protein kinase C stimulates the acid-sensing ion channel ASIC2a via the PDZ domain-containing protein PICK1. J Biol Chem, 277(52), 50463-50468. doi:10.1074/jbc.M208848200

Baron, A., Schaefer, L., Lingueglia, E., Champigny, G., \& Lazdunski, M. (2001). Zn2+ and H+ are coactivators of acid-sensing ion channels. J Biol Chem, 276(38), 35361-35367. doi:10.1074/jbc.M105208200

Baron, A., Voilley, N., Lazdunski, M., \& Lingueglia, E. (2008). Acid sensing ion channels in dorsal spinal cord neurons. J Neurosci, 28(6), 1498-1508. doi:10.1523/jneurosci.4975-07.2008

Bartoi, T., Augustinowski, K., Polleichtner, G., Grunder, S., \& Ulbrich, M. H. (2014). Acid-sensing ion channel (ASIC) 1a/2a heteromers have a flexible 2:1/1:2 stoichiometry. Proc Natl Acad Sci U S A, 111(22), 8281-8286. doi:10.1073/pnas.1324060111

Bassler, E. L., Ngo-Anh, T. J., Geisler, H. S., Ruppersberg, J. P., \& Grunder, S. (2001). Molecular and functional characterization of acid-sensing ion channel (ASIC) 1b. J Biol Chem, 276(36), 33782-33787. doi:10.1074/jbc.M104030200

Baydyuk, M., Xu, J., \& Wu, L. G. (2016). The calyx of Held in the auditory system: Structure, function, and development. Hear Res, 338, 22-31. doi: 10.1016/j.heares.2016.03.009

Beckwith-Cohen B, Holzhausen LC, Wang TM, Rajappa R, Kramer RH. Localizing Proton-Mediated Inhibitory Feedback at the Retinal Horizontal Cell-Cone Synapse with Genetically-Encoded pH Probes. J Neurosci. 2019 Jan 23;39(4):651-662.

Beg, A. A., Ernstrom, G. G., Nix, P., Davis, M. W., \& Jorgensen, E. M. (2008). Protons act as a transmitter for muscle contraction in C. elegans. Cell, 132(1), 149-160. doi: 10.1016/j.cell.2007.10.058

Benson, C. J., Xie, J., Wemmie, J. A., Price, M. P., Henss, J. M., Welsh, M. J., \& Snyder, P. M. (2002). Heteromultimers of DEG/ENaC subunits form $\mathrm{H}+$-gated channels in mouse sensory neurons. Proc Natl Acad Sci U S A, 99(4), 2338-2343. doi:10.1073/pnas.032678399

Bohlen, C. J., Chesler, A. T., Sharif-Naeini, R., Medzihradszky, K. F., Zhou, S., King, D., . . . Julius, D. (2011). A heteromeric Texas coral snake toxin targets acid-sensing ion channels to produce pain. Nature, 479(7373), 410-414. doi:10.1038/nature10607

Boiko, N., Kucher, V., Eaton, B. A., \& Stockand, J. D. (2013). Inhibition of neuronal degenerin/epithelial $\mathrm{Na}+$ channels by the multiple sclerosis drug 4-aminopyridine. J Biol Chem, 288(13), 9418-9427. doi:10.1074/jbc.M112.449413

Borst, J. G., \& Soria van Hoeve, J. (2012). The calyx of Held synapse: from model synapse to auditory relay. Annu Rev Physiol, 74, 199-224. doi:10.1146/annurev-physiol-020911-153236

This article is protected by copyright. All rights reserved. 
Buta, A., Maximyuk, O., Kovalskyy, D., Sukach, V., Vovk, M., levglevskyi, O., . . Krishtal, O. (2015). Novel Potent Orthosteric Antagonist of ASIC1a Prevents NMDAR-Dependent LTP Induction. J Med Chem, 58(11), 4449-4461. doi:10.1021/jm5017329

Cadiou, H., Studer, M., Jones, N. G., Smith, E. S., Ballard, A., McMahon, S. B., \& McNaughton, P. A. (2007). Modulation of acid-sensing ion channel activity by nitric oxide. J Neurosci, 27(48), 1325113260. doi:10.1523/jneurosci.2135-07.2007

Carnally, S. M., Dev, H. S., Stewart, A. P., Barrera, N. P., Van Bemmelen, M. X., Schild, L., . . . Edwardson, J. M. (2008). Direct visualization of the trimeric structure of the ASIC1a channel, using AFM imaging. Biochem Biophys Res Commun, 372(4), 752-755. doi: 10.1016/j.bbrc.2008.05.100

Catterall, W. A. (2000). Structure and regulation of voltage-gated Ca2+ channels. Annu Rev Cell Dev Biol, 16, 521-555. doi: 10.1146/annurev.cellbio.16.1.521

Champigny, G., Voilley, N., Waldmann, R., \& Lazdunski, M. (1998). Mutations causing neurodegeneration in Caenorhabditis elegans drastically alter the $\mathrm{pH}$ sensitivity and inactivation of the mammalian H+-gated Na+ channel MDEG1. J Biol Chem, 273(25), 15418-15422.

Chen, X., Kalbacher, H., \& Grunder, S. (2005). The tarantula toxin psalmotoxin 1 inhibits acid-sensing ion channel (ASIC) 1a by increasing its apparent H+ affinity. J Gen Physiol, 126(1), 71-79. doi:10.1085/jgp.200509303

Chen, X., Kalbacher, H., \& Grunder, S. (2006). Interaction of acid-sensing ion channel (ASIC) 1 with the tarantula toxin psalmotoxin 1 is state dependent. J Gen Physiol, 127(3), 267-276. doi:10.1085/jgp.200509409

Chen, X., Qiu, L., Li, M., Durrnagel, S., Orser, B. A., Xiong, Z. G., \& MacDonald, J. F. (2010). Diarylamidines: high potency inhibitors of acid-sensing ion channels. Neuropharmacology, 58(7), 1045-1053. doi: 10.1016/j.neuropharm.2010.01.011

Chesler, M. (2003). Regulation and modulation of pH in the brain. Physiol Rev, 83(4), 1183-1221. doi:10.1152/physrev.00010.2003

Chiang, P. H., Chien, T. C., Chen, C. C., Yanagawa, Y., \& Lien, C. C. (2015). ASIC-dependent LTP at multiple glutamatergic synapses in amygdala network is required for fear memory. Sci Rep, 5, 10143. doi:10.1038/srep10143

Cho, J. H., \& Askwith, C. C. (2007). Potentiation of acid-sensing ion channels by sulfhydryl compounds. Am J Physiol Cell Physiol, 292(6), C2161-2174. doi:10.1152/ajpcell.00598.2006

Cho, J. H., \& Askwith, C. C. (2008). Presynaptic release probability is increased in hippocampal neurons from ASIC1 knockout mice. J Neurophysiol, 99(2), 426-441. doi:10.1152/jn.00940.2007

This article is protected by copyright. All rights reserved. 
Cho, S., \& von Gersdorff, H. (2014). Proton-mediated block of Ca2+ channels during multivesicular release regulates short-term plasticity at an auditory hair cell synapse. J Neurosci, 34(48), 1587715887. doi:10.1523/jneurosci.2304-14.2014

Chu, X. P., Close, N., Saugstad, J. A., \& Xiong, Z. G. (2006). ASIC1a-specific modulation of acid-sensing ion channels in mouse cortical neurons by redox reagents. J Neurosci, 26(20), 5329-5339. doi:10.1523/jneurosci.0938-06.2006

Chu, X. P., Miesch, J., Johnson, M., Root, L., Zhu, X. M., Chen, D., .. Xiong, Z. G. (2002). Proton-gated channels in PC12 cells. J Neurophysiol, 87(5), 2555-2561. doi:10.1152/jn.00741.2001

Clements, J. D. (1996). Transmitter timecourse in the synaptic cleft: its role in central synaptic function. Trends Neurosci, 19(5), 163-171.

Cristofori-Armstrong, B., \& Rash, L. D. (2017). Acid-sensing ion channel (ASIC) structure and function: Insights from spider, snake and sea anemone venoms. Neuropharmacology, 127, 173-184. doi: 10.1016/j.neuropharm.2017.04.042

Cukierman, S. (2006). Et tu, Grotthuss! and other unfinished stories. Biochim Biophys Acta, 1757(8), 876-885. doi:10.1016/j.bbabio.2005.12.001

De Robertis, E., Rodriguez De Lores Arnaiz, G., \& Pellegrino De Iraldi, A. (1962). Isolation of synaptic vesicles from nerve endings of the rat brain. Nature, 194, 794-795.

Deval, E., Noel, J., Lay, N., Alloui, A., Diochot, S., Friend, V., . . Lingueglia, E. (2008). ASIC3, a sensor of acidic and primary inflammatory pain. Embo j, 27(22), 3047-3055. doi:10.1038/emboj.2008.213

DeVries, S. H. (2001). Exocytosed protons feedback to suppress the Ca2+ current in mammalian cone photoreceptors. Neuron, 32(6), 1107-1117.

Dietrich, C. J., \& Morad, M. (2010). Synaptic acidification enhances GABAA signaling. J Neurosci, 30(47), 16044-16052. doi:10.1523/jneurosci.6364-09.2010

Diochot, S., Alloui, A., Rodrigues, P., Dauvois, M., Friend, V., Aissouni, Y., . . Baron, A. (2016). Analgesic effects of mambalgin peptide inhibitors of acid-sensing ion channels in inflammatory and neuropathic pain. Pain, 157(3), 552-559. doi: 10.1097/j.pain.0000000000000397

Dorofeeva, N. A., Barygin, O. I., Staruschenko, A., Bolshakov, K. V., \& Magazanik, L. G. (2008). Mechanisms of non-steroid anti-inflammatory drugs action on ASICs expressed in hippocampal interneurons. J Neurochem, 106(1), 429-441. doi:10.1111/j.1471-4159.2008. 05412.x

Du, J., Reznikov, L. R., Price, M. P., Zha, X. M., Lu, Y., Moninger, T. O., ... Welsh, M. J. (2014). Protons are a neurotransmitter that regulates synaptic plasticity in the lateral amygdala. Proc Natl Acad Sci U S A, 111(24), 8961-8966. doi:10.1073/pnas.1407018111

This article is protected by copyright. All rights reserved. 
Duan, B., Wang, Y. Z., Yang, T., Chu, X. P., Yu, Y., Huang, Y., . . Xu, T. L. (2011). Extracellular spermine exacerbates ischemic neuronal injury through sensitization of ASIC1a channels to extracellular acidosis. J Neurosci, 31(6), 2101-2112. doi:10.1523/jneurosci.4351-10.2011

Dube, G. R., Elagoz, A., \& Mangat, H. (2009). Acid sensing ion channels and acid nociception. Curr Pharm Des, 15(15), 1750-1766.

Dube, G. R., Lehto, S. G., Breese, N. M., Baker, S. J., Wang, X., Matulenko, M. A., . . Brioni, J. D. (2005). Electrophysiological and in vivo characterization of A-317567, a novel blocker of acid sensing ion channels. Pain, 117(1-2), 88-96. doi: 10.1016/j.pain.2005.05.021

Er, S. Y., Cristofori-Armstrong, B., Escoubas, P., \& Rash, L. D. (2017). Discovery and molecular interaction studies of a highly stable, tarantula peptide modulator of acid-sensing ion channel 1. Neuropharmacology, 127, 185-195. doi: 10.1016/j.neuropharm.2017.03.020

Escoubas, P., Diochot, S., \& Corzo, G. (2000). Structure and pharmacology of spider venom neurotoxins. Biochimie, 82(9-10), 893-907.

Farooqui, A. A., \& Horrocks, L. A. (2006). Phospholipase A2-generated lipid mediators in the brain: the good, the bad, and the ugly. Neuroscientist, 12(3), 245-260. doi:10.1177/1073858405285923 Fedirko, N., Svichar, N., \& Chesler, M. (2006). Fabrication and use of high-speed, concentric h+- and Ca2+-selective microelectrodes suitable for in vitro extracellular recording. J Neurophysiol, 96(2), 919-924. doi:10.1152/jn.00258.2006

Gao, J., Wu, L. J., Xu, L., \& Xu, T. L. (2004). Properties of the proton-evoked currents and their modulation by $\mathrm{Ca} 2+$ and $\mathrm{Zn} 2+$ in the acutely dissociated hippocampus CA1 neurons. Brain Res, 1017(1-2), 197-207. doi:10.1016/j.brainres.2004.05.046

Garza, A., Lopez-Ramirez, O., Vega, R., \& Soto, E. (2010). The aminoglycosides modulate the acidsensing ionic channel currents in dorsal root ganglion neurons from the rat. J Pharmacol Exp Ther, 332(2), 489-499. doi:10.1124/jpet.109.152884

Ghobbeh, A., Taugher, R. J., Alam, S. M., Fan, R., LaLumiere, R. T., \& Wemmie, J. A. (2018). A novel role for acid-sensing ion channels in Pavlovian reward conditioning. Genes Brain Behav, e12531. doi:10.1111/gbb.12531

González Inchauspe C., Gobetto N. \& Uchitel O.D. (2919) Modulation of acid sensing ion channel dependent protonergic neurotransmission at the mouse calyx of Held. Neuroscience, "in press",

Gonzalez-Inchauspe, C., Urbano, F. J., Di Guilmi, M. N., \& Uchitel, O. D. (2017). Acid-Sensing Ion Channels Activated by Evoked Released Protons Modulate Synaptic Transmission at the Mouse Calyx of Held Synapse. J Neurosci, 37(10), 2589-2599. doi:10.1523/jneurosci.2566-16.2017

Grunder, S., \& Pusch, M. (2015). Biophysical properties of acid-sensing ion channels (ASICs). Neuropharmacology, 94, 9-18. doi: 10.1016/j.neuropharm.2014.12.016

This article is protected by copyright. All rights reserved. 
Guerra, G. P., Rubin, M. A., \& Mello, C. F. (2016). Modulation of learning and memory by natural polyamines. Pharmacol Res, 112, 99-118. doi: 10.1016/j.phrs.2016.03.023

Gutman, A. L., Cosme, C. V., Noterman, M. F., Worth, W. R., Wemmie, J. A., \& LaLumiere, R. T. (2018). Overexpression of ASIC1A in the nucleus accumbens of rats potentiates cocaine-seeking behavior. Addict Biol. doi:10.1111/adb.12690

Hansen KB, Yi F, Perszyk RE, Furukawa H, Wollmuth LP, Gibb AJ, Traynelis SF. Structure, function, and allosteric modulation of NMDA receptors. J Gen Physiol. 2018 Aug 6;150(8):1081-1105.

Hattori, T., Chen, J., Harding, A. M., Price, M. P., Lu, Y., Abboud, F. M., \& Benson, C. J. (2009). ASIC2a and ASIC3 heteromultimerize to form $\mathrm{pH}$-sensitive channels in mouse cardiac dorsal root ganglia neurons. Circ Res, 105(3), 279-286. doi:10.1161/circresaha.109.202036

Hesselager, M., Timmermann, D. B., \& Ahring, P. K. (2004). pH Dependency and desensitization kinetics of heterologously expressed combinations of acid-sensing ion channel subunits. J Biol Chem, 279(12), 11006-11015. doi:10.1074/jbc.M313507200

Highstein, S. M., Holstein, G. R., Mann, M. A., \& Rabbitt, R. D. (2014). Evidence that protons act as neurotransmitters at vestibular hair cell-calyx afferent synapses. Proc Natl Acad Sci U S A, 111(14), 5421-5426. doi:10.1073/pnas.1319561111

Hirasawa H, Kaneko A. (2003). pH changes in the invaginating synaptic cleft mediate feedback from horizontal cells to cone photoreceptors by modulating Ca2+ channels. J Gen Physiol. Dec;122(6):65771.

Hoagland, E. N., Sherwood, T. W., Lee, K. G., Walker, C. J., \& Askwith, C. C. (2010). Identification of a calcium permeable human acid-sensing ion channel 1 transcript variant. J Biol Chem, 285(53), 4185241862. doi:10.1074/jbc.M110.171330

Hruska-Hageman AM, Wemmie JA, Price MP, Welsh MJ. (2002). Interaction of the synaptic protein PICK1 (protein interacting with C kinase 1) with the non-voltage gated sodium channels BNC1 (brain $\mathrm{Na}+$ channel 1) and ASIC (acid-sensing ion channel). Biochem J, 361(Pt 3):443-50.

levglevskyi, O., Isaev, D., Netsyk, O., Romanov, A., Fedoriuk, M., Maximyuk, O., . . Krishtal, O. (2016). Acid-sensing ion channels regulate spontaneous inhibitory activity in the hippocampus: possible implications for epilepsy. Philos Trans R Soc Lond B Biol Sci, 371(1700). doi:10.1098/rstb.2015.0431

lijima, T., Ciani, S., \& Hagiwara, S. (1986). Effects of the external pH on Ca channels: experimental studies and theoretical considerations using a two-site, two-ion model. Proc Natl Acad Sci U S A, $83(3), 654-658$.

Immke, D. C., \& McCleskey, E. W. (2001). Lactate enhances the acid-sensing Na+ channel on ischemia-sensing neurons. Nat Neurosci, 4(9), 869-870. doi:10.1038/nn0901-869

This article is protected by copyright. All rights reserved. 
Immke, D. C., \& McCleskey, E. W. (2003). Protons open acid-sensing ion channels by catalyzing relief of Ca2+ blockade. Neuron, 37(1), 75-84.

Jasti, J., Furukawa, H., Gonzales, E. B., \& Gouaux, E. (2007). Structure of acid-sensing ion channel 1 at 1.9 A resolution and low pH. Nature, 449(7160), 316-323. doi:10.1038/nature06163

Jiang, Q., Li, M. H., Papasian, C. J., Branigan, D., Xiong, Z. G., Wang, J. Q., \& Chu, X. P. (2009). Characterization of acid-sensing ion channels in medium spiny neurons of mouse striatum. Neuroscience, 162(1), 55-66. doi: 10.1016/j.neuroscience.2009.04.029

Kaila, K. (1994). Ionic basis of GABAA receptor channel function in the nervous system. Prog Neurobiol, 42(4), 489-537.

Kalina, R., Gladkikh, I., Dmitrenok, P., Chernikov, O., Koshelev, S., Kvetkina, A., . . Monastyrnaya, M. (2018). New APETx-like peptides from sea anemone Heteractis crispa modulate ASIC1a channels. Peptides, 104, 41-49. doi: 10.1016/j.peptides.2018.04.013

Katz, B. (2003). Neural transmitter release: from quantal secretion to exocytosis and beyond. J Neurocytol, 32(5-8), 437-446. doi:10.1023/b: Neur.0000020603.84188.03

Kellenberger, S., \& Schild, L. (2015). International Union of Basic and Clinical Pharmacology. XCI. structure, function, and pharmacology of acid-sensing ion channels and the epithelial $\mathrm{Na}+$ channel. Pharmacol Rev, 67(1), 1-35. doi:10.1124/pr.114.009225

Kini, R. M., \& Doley, R. (2010). Structure, function and evolution of three-finger toxins: mini proteins with multiple targets. Toxicon, 56(6), 855-867. doi: 10.1016/j.toxicon.2010.07.010

Klockner, U., \& Isenberg, G. (1994). Calcium channel current of vascular smooth muscle cells: extracellular protons modulate gating and single channel conductance. J Gen Physiol, 103(4), 665678.

Kohler, C. A., da Silva, W. C., Benetti, F., \& Bonini, J. S. (2011). Histaminergic mechanisms for modulation of memory systems. Neural Plast, 2011, 328602. doi:10.1155/2011/328602

Koike-Tani, M., Kanda, T., Saitoh, N., Yamashita, T., \& Takahashi, T. (2008). Involvement of AMPA receptor desensitization in short-term synaptic depression at the calyx of Held in developing rats. J Physiol, 586(9), 2263-2275. doi:10.1113/jphysiol.2007.142547

Korkushko, A. O., \& Kryshtal, O. A. (1984). [Blocking of proton-activated sodium permeability of the membranes of trigeminal ganglion neurons in the rat by organic cations]. Neirofiziologiia, 16(4), 557561.

Kozlov, S. A., Osmakov, D. I., Andreev la, A., Koshelev, S. G., Gladkikh, I. N., Monastyrnaia, M. M., . . Grishin, E. V. (2012). [Polypeptide toxin from sea anemone inhibiting proton-sensitive channel ASIC3]. Bioorg Khim, 38(6), 653-659. 
Krauson, A. J., Rooney, J. G., \& Carattino, M. D. (2018). Molecular basis of inhibition of acid sensing ion channel 1A by diminazene. PLoS One, 13(5), e0196894. doi: 10.1371/journal.pone.0196894

Krauson, A. J., Rued, A. C., \& Carattino, M. D. (2013). Independent contribution of extracellular proton binding sites to ASIC1a activation. J Biol Chem, 288(48), 34375-34383. doi:10.1074/jbc.M113.504324

Kreple, C. J., Lu, Y., Taugher, R. J., Schwager-Gutman, A. L., Du, J., Stump, M., . . Wemmie, J. A. (2014). Acid-sensing ion channels contribute to synaptic transmission and inhibit cocaine-evoked plasticity. Nat Neurosci, 17(8), 1083-1091. doi:10.1038/nn.3750

Krishtal, O. A., Osipchuk, Y. V., Shelest, T. N., \& Smirnoff, S. V. (1987). Rapid extracellular pH transients related to synaptic transmission in rat hippocampal slices. Brain Res, 436(2), 352-356.

Krishtal, O. A., \& Pidoplichko, V. I. (1981). A "receptor" for protons in small neurons of trigeminal ganglia: possible role in nociception. Neurosci Lett, 24(3), 243-246.

Lefevre, C. M., Diakov, A., Haerteis, S., Korbmacher, C., Grunder, S., \& Wiemuth, D. (2014). Pharmacological and electrophysiological characterization of the human bile acid-sensitive ion channel (hBASIC). Pflugers Arch, 466(2), 253-263. doi:10.1007/s00424-013-1310-4

Lei, S., Orser, B. A., Thatcher, G. R., Reynolds, J. N., \& MacDonald, J. F. (2001). Positive allosteric modulators of AMPA receptors reduce proton-induced receptor desensitization in rat hippocampal neurons. J Neurophysiol, 85(5), 2030-2038. doi:10.1152/jn.2001.85.5.2030

Lei, Z., Li, X., Wang, G., Fei, J., Meng, T., Zhang, X., . . . Li, J. (2014). Inhibition of acid-sensing ion channel currents by propofol in rat dorsal root ganglion neurons. Clin Exp Pharmacol Physiol, 41(4), 295-300. doi:10.1111/1440-1681.12215

Leng, T. D., \& Xiong, Z. G. (2013). The pharmacology and therapeutic potential of small molecule inhibitors of acid-sensing ion channels in stroke intervention. Acta Pharmacol Sin, 34(1), 33-38. doi:10.1038/aps.2012.81

Li, M., Kratzer, E., Inoue, K., Simon, R. P., \& Xiong, Z. G. (2010). Developmental change in the electrophysiological and pharmacological properties of acid-sensing ion channels in CNS neurons. J Physiol, 588(Pt 20), 3883-3900. doi:10.1113/jphysiol.2010.192922

Li HS, Su XY, Song XL, Qi X, Li Y, Wang RQ, Maximyuk O, Krishtal O, Wang T, Fang H, Liao L, Cao H, Zhang YQ, Zhu MX, Liu MG, Xu TL.(2019) Protein kinase C lambdamediates acid-sensing ion channel 1a-dependent cortical synaptic plasticity and pain hypersensitivity. J Neurosci. 2019 May 17. pii: 0213-19. doi: 10.1523/JNEUROSCI.0213-19.2019. [Epub ahead of print]

Li, W. G., Liu, M. G., Deng, S., Liu, Y. M., Shang, L., Ding, J, Xu, T. L. (2016). ASIC1a regulates insular long-term depression and is required for the extinction of conditioned taste aversion. Nat Commun, 7, 13770. doi:10.1038/ncomms13770 
Liechti, L. A., Berneche, S., Bargeton, B., Iwaszkiewicz, J., Roy, S., Michielin, O., \& Kellenberger, S. (2010). A combined computational and functional approach identifies new residues involved in $\mathrm{pH}-$ dependent gating of ASIC1a. J Biol Chem, 285(21), 16315-16329. doi:10.1074/jbc.M109.092015 Lin, J. H., Chiang, Y. H., \& Chen, C. C. (2015). Research strategies for pain in lumbar radiculopathy focusing on acid-sensing ion channels and their toxins. Curr Top Med Chem, 15(7), 617-630.

Lingueglia, E., de Weille, J. R., Bassilana, F., Heurteaux, C., Sakai, H., Waldmann, R., \& Lazdunski, M. (1997). A modulatory subunit of acid sensing ion channels in brain and dorsal root ganglion cells. J Biol Chem, 272(47), 29778-29783.

Liu, M. G., Li, H. S., Li, W. G., Wu, Y. J., Deng, S. N., Huang, C., . . Xu, T. L. (2016). Acid-sensing ion channel 1a contributes to hippocampal LTP inducibility through multiple mechanisms. Sci Rep, 6, 23350. doi:10.1038/srep23350

Liu, Y., \& Edwards, R. H. (1997). The role of vesicular transport proteins in synaptic transmission and neural degeneration. Annu Rev Neurosci, 20, 125-156. doi: 10.1146/annurev.neuro.20.1.125

Liu, Y., Hagan, R., \& Schoellerman, J. (2018). Dual actions of Psalmotoxin at ASIC1a and ASIC2a heteromeric channels (ASIC1a/2a). Sci Rep, 8(1), 7179. doi:10.1038/s41598-018-25386-9

Ludwig MG, Vanek M, Guerini D, Gasser JA, Jones CE, Junker U, et al. Proton-sensing G-proteincoupled receptors. Nature 2003; 425: 93-8.

Lujan B, Dagostin A, von Gersdorff H. Presynaptic Diversity Revealed by $\mathrm{Ca}(2+)-$ Permeable AMPA Receptors at the Calyx of Held Synapse. J Neurosci:39(16):2981-2994. doi: 10.1523/JNEUROSCI.256518.2019. Epub 2019 Jan 24.

Lynagh T, Romero-Rojo JL, Lund C, Pless SA. Molecular Basis for Allosteric Inhibition of Acid-Sensing Ion Channel 1a by Ibuprofen. J Med Chem. 2017 60(19):8192-8200. doi:10.1021/acs.jmedchem.7b01072.

Lynagh, T., Mikhaleva, Y., Colding, J. M., Glover, J. C., \& Pless, S. A. (2018). Acid-sensing ion channels emerged over 600 Mya and are conserved throughout the deuterostomes. Proc Natl Acad Sci U S A, 115(33), 8430-8435. doi:10.1073/pnas.1806614115

MacLean, D. M., \& Jayaraman, V. (2016). Acid-sensing ion channels are tuned to follow highfrequency stimuli. J Physiol, 594(10), 2629-2645. doi:10.1113/jp271915

MacLean, D. M., \& Jayaraman, V. (2017). Deactivation kinetics of acid-sensing ion channel 1a are strongly pH-sensitive. Proc Natl Acad Sci U S A, 114(12), E2504-e2513. doi:10.1073/pnas.1620508114

Makani, S., \& Chesler, M. (2007). Endogenous alkaline transients boost postsynaptic NMDA receptor responses in hippocampal CA1 pyramidal neurons. J Neurosci, 27(28), 7438-7446. doi:10.1523/jneurosci.2304-07.2007 
Makani, S., \& Chesler, M. (2010a). Barium plateau potentials of CA1 pyramidal neurons elicit all-ornone extracellular alkaline shifts via the plasma membrane calcium ATPase. J Neurophysiol, 104(3), 1438-1444. doi:10.1152/jn.00504.2010

Makani, S., \& Chesler, M. (2010b). Rapid rise of extracellular pH evoked by neural activity is generated by the plasma membrane calcium ATPase. J Neurophysiol, 103(2), 667-676. doi:10.1152/jn.00948.2009

Meyer, A. C., Neher, E., \& Schneggenburger, R. (2001). Estimation of quantal size and number of functional active zones at the calyx of Held synapse by nonstationary EPSC variance analysis. J Neurosci, 21(20), 7889-7900.

Miesenbock, G., De Angelis, D. A., \& Rothman, J. E. (1998). Visualizing secretion and synaptic transmission with pH-sensitive green fluorescent proteins. Nature, 394(6689), 192-195. doi:10.1038/28190

Mourier, G., Salinas, M., Kessler, P., Stura, E. A., Leblanc, M., Tepshi, L., . . Servent, D. (2016). Mambalgin-1 Pain-relieving Peptide, Stepwise Solid-phase Synthesis, Crystal Structure, and Functional Domain for Acid-sensing Ion Channel 1a Inhibition. J Biol Chem, 291(6), 2616-2629. doi:10.1074/jbc.M115.702373

Munro, G., Christensen, J. K., Erichsen, H. K., Dyhring, T., Demnitz, J., Dam, E., \& Ahring, P. K. (2016). NS383 Selectively Inhibits Acid-Sensing Ion Channels Containing 1a and 3 Subunits to Reverse Inflammatory and Neuropathic Hyperalgesia in Rats. CNS Neurosci Ther, 22(2), 135-145. doi:10.1111/cns.12487

Nagaeva, E. I., Potapieva, N. N., Nikolaev, M. V., Gmiro, V. E., Magazanik, L. G., \& Tikhonov, D. B. (2016). Determinants of action of hydrophobic amines on ASIC1a and ASIC2a. Eur J Pharmacol, 788, 75-83. doi: 10.1016/j.ejphar.2016.06.013

Neher E, Taschenberger H. (2013) Transients in global Ca2+ concentration induced by electrical activity in a giant nerve terminal. J Physiol.:591(13):3189-95. doi: 10.1113/jphysiol.2012.248617.

Nikolaev, M., Komarova, M., Tikhonova, T., Korosteleva, A., Potapjeva, N., \& Tikhonov, D. B. (2018). Modulation of proton-gated channels by antidepressants. ACS Chem Neurosci. doi:10.1021/acschemneuro.8b00560

Osmakov, D. I., Andreev, Y. A., \& Kozlov, S. A. (2014). Acid-sensing ion channels and their modulators. Biochemistry (Mosc), 79(13), 1528-1545. doi:10.1134/s0006297914130069

Ostrovskaya, O., Moroz, L., \& Krishtal, O. (2004). Modulatory action of RFamide-related peptides on acid-sensing ionic channels is pH dependent: the role of arginine. J Neurochem, 91(1), 252-255. doi:10.1111/j.1471-4159.2004. 02688.x 
Packard, M. G., \& Knowlton, B. J. (2002). Learning and memory functions of the Basal Ganglia. Annu Rev Neurosci, 25, 563-593. doi: 10.1146/annurev.neuro.25.112701.142937

Palmer, M. J., Hull, C., Vigh, J., \& von Gersdorff, H. (2003). Synaptic cleft acidification and modulation of short-term depression by exocytosed protons in retinal bipolar cells. J Neurosci, 23(36), 1133211341.

Panula, P., \& Nuutinen, S. (2013). The histaminergic network in the brain: basic organization and role in disease. Nat Rev Neurosci, 14(7), 472-487. doi:10.1038/nrn3526

Paukert, M., Chen, X., Polleichtner, G., Schindelin, H., \& Grunder, S. (2008). Candidate amino acids involved in $\mathrm{H}+$ gating of acid-sensing ion channel 1a. J Biol Chem, 283(1), 572-581. doi:10.1074/jbc.M706811200

Paukert, M., Sidi, S., Russell, C., Siba, M., Wilson, S. W., Nicolson, T., \& Grunder, S. (2004). A family of acid-sensing ion channels from the zebrafish: widespread expression in the central nervous system suggests a conserved role in neuronal communication. J Biol Chem, 279(18), 18783-18791. doi:10.1074/jbc.M401477200

Perissinotti, P. P., \& Uchitel, O. D. (2010). Adenosine drives recycled vesicles to a slow-release pool at the mouse neuromuscular junction. Eur J Neurosci, 32(6), 985-996. doi:10.1111/j.1460-9568.2010. 07332.x

Price, M. P., Gong, H., Parsons, M. G., Kundert, J. R., Reznikov, L. R., Bernardinelli, L., . . Welsh, M. J. (2014). Localization and behaviors in null mice suggest that ASIC1 and ASIC2 modulate responses to aversive stimuli. Genes Brain Behav, 13(2), 179-194. doi:10.1111/gbb.12108

Rash, L. D. (2017). Acid-Sensing Ion Channel Pharmacology, Past, Present, and Future. Adv Pharmacol, 79, 35-66. doi: 10.1016/bs.apha.2017.02.001

Reeh PW, Kress M. Molecular physiology of proton transduction in nociceptors. Curr Opin Pharmacol 2001; 1: 45-51

Rose, C. R., \& Deitmer, J. W. (1994). Evidence that glial cells modulate extracellular pH transients induced by neuronal activity in the leech central nervous system. J Physiol, 481 (Pt 1), 1-5.

Samways, D. S., Harkins, A. B., \& Egan, T. M. (2009). Native and recombinant ASIC1a receptors conduct negligible Ca2+ entry. Cell Calcium, 45(4), 319-325. doi: 10.1016/j.ceca.2008.12.002

Schroeder, C. I., Rash, L. D., Vila-Farres, X., Rosengren, K. J., Mobli, M., King, G. F., . . Durek, T. (2014). Chemical synthesis, 3D structure, and ASIC binding site of the toxin mambalgin-2. Angew Chem Int Ed Engl, 53(4), 1017-1020. doi:10.1002/anie.201308898

Sherin, J. E., Elmquist, J. K., Torrealba, F., \& Saper, C. B. (1998). Innervation of histaminergic tuberomammillary neurons by GABAergic and galaninergic neurons in the ventrolateral preoptic nucleus of the rat. J Neurosci, 18(12), 4705-4721.

This article is protected by copyright. All rights reserved. 
Sherwood, T.W., Franke, R., Conneely, S., Joyner, J., Arumugan, P., \& Askwith, C. (2009). Identification of protein domains that control proton and calcium sensitivity of ASIC1a. J Biol Chem, 284(41), 27899-27907. doi:10.1074/jbc.M109.029009

Sherwood, T.W, Lee K.G, Gormley M.G, Askwith C.C. (2011) Heteromeric acid-sensing ion channels (ASICs) composed of ASIC2b and ASIC1a display novel channel properties and contribute to acidosisinduced neuronal death. J Neurosci. 31(26):9723-34. doi: 10.1523/JNEUROSCI.1665-11.2011.

Sherwood, T. W., \& Askwith, C. C. (2008). Endogenous arginine-phenylalanine-amide-related peptides alter steady-state desensitization of ASIC1a. J Biol Chem, 283(4), 1818-1830. doi:10.1074/jbc.M705118200

Shteinikov, V. Y., Barygin, O. I., Gmiro, V. E., \& Tikhonov, D. B. (2019). Multiple modes of action of hydrophobic amines and their guanidine analogues on ASIC1a. Eur J Pharmacol, 844, 183-194. doi: 10.1016/j.ejphar.2018.12.024

Shteinikov, V. Y., Korosteleva, A. S., Tikhonova, T. B., Potapieva, N. N., \& Tikhonov, D. B. (2017). Ligands of histamine receptors modulate acid-sensing ion channels. Biochem Biophys Res Commun, 490(4), 1314-1318. doi: 10.1016/j.bbrc.2017.07.019

Shteinikov, V. Y., Tikhonova, T. B., Korkosh, V. S., \& Tikhonov, D. B. (2018). Potentiation and Block of ASIC1a by Memantine. Cell Mol Neurobiol, 38(4), 869-881. doi:10.1007/s10571-017-0561-6

Sinning, A., \& Hubner, C. A. (2013). Minireview: pH and synaptic transmission. FEBS Lett, 587(13), 1923-1928. doi: 10.1016/j.febslet.2013.04.045

Smith, E. S., Cadiou, H., \& McNaughton, P. A. (2007). Arachidonic acid potentiates acid-sensing ion channels in rat sensory neurons by a direct action. Neuroscience, 145(2), 686-698. doi: 10.1016/j.neuroscience.2006.12.024

Südhof TC, The presynaptic active zone, Neuron. 2012 Jul 12;75(1):11-25.

Suman, A., Mehta, B., Guo, M. L., Chu, X. P., Fibuch, E. E., Mao, L. M., \& Wang, J. Q. (2010). Alterations in subcellular expression of acid-sensing ion channels in the rat forebrain following chronic amphetamine administration. Neurosci Res, 68(1), 1-8. doi: 10.1016/j.neures.2010.06.001

Sutherland, S. P., Benson, C. J., Adelman, J. P., \& McCleskey, E. W. (2001). Acid-sensing ion channel 3 matches the acid-gated current in cardiac ischemia-sensing neurons. Proc Natl Acad Sci U S A, 98(2), 711-716. doi:10.1073/pnas.011404498

Taschenberger H, Leão RM, Rowland KC, Spirou GA, von Gersdorff H. (2002). Optimizing synaptic architecture and efficiency for high-frequency transmission. Neuron :36(6):1127-43.

Thoreson WB, Mangel SC. (2012) Lateral interactions in the outer retina. Prog RetinEye Res. 2012 Sep;31(5):407-41. doi: 10.1016/j.preteyeres.2012 
Traynelis, S. F., \& Cull-Candy, S. G. (1990). Proton inhibition of N-methyl-D-aspartate receptors in cerebellar neurons. Nature, 345(6273), 347-350. doi:10.1038/345347a0

Traynelis, S. F., \& Cull-Candy, S. G. (1991). Pharmacological properties and H+ sensitivity of excitatory amino acid receptor channels in rat cerebellar granule neurones. J Physiol, 433, 727-763.

Urbanics, R., Leniger-Follert, E., \& Lubbers, D. W. (1978). Time course of changes of extracellular H+ and $\mathrm{K}+$ activities during and after direct electrical stimulation of the brain cortex. Pflugers Arch, 378(1), 47-53.

Urbano, F. J., Lino, N. G., Gonzalez-Inchauspe, C. M., Gonzalez, L. E., Colettis, N., Vattino, L. G., . . . Uchitel, O. D. (2014). Acid-sensing ion channels 1a (ASIC1a) inhibit neuromuscular transmission in female mice. Am J Physiol Cell Physiol, 306(4), C396-406. doi:10.1152/ajpcell.00301.2013

Vannucci, S. J., \& Hagberg, H. (2004). Hypoxia-ischemia in the immature brain. J Exp Biol, 207(Pt 18), 3149-3154. doi:10.1242/jeb.01064

Vassilevski, A. A., Kozlov, S. A., \& Grishin, E. V. (2009). Molecular diversity of spider venom. Biochemistry (Mosc), 74(13), 1505-1534.

Vessey JP, Stratis AK, Daniels BA, Da Silva N, Jonz MG, Lalonde MR, Baldridge WH, Barnes S. (2005). Proton-mediated feedback inhibition of presynaptic calcium channels at the cone photoreceptor synapse. J Neurosci. 25(16):4108-17.

Vick, J. S., \& Askwith, C. C. (2015). ASICs and neuropeptides. Neuropharmacology, 94, 36-41. doi: 10.1016/j.neuropharm.2014.12.012

Vincent PFY, Cho S, Tertrais M, Bouleau Y, von Gersdorff H, Dulon D. Clustered Ca(2+) Channels Are Blocked by Synaptic Vesicle Proton Release at Mammalian Auditory Ribbon Synapses. Cell Rep.:25(12):3451-3464.e3. doi: 10.1016/j.celrep.2018.11.072.

Vitrac, C., \& Benoit-Marand, M. (2017). Monoaminergic Modulation of Motor Cortex Function. Front Neural Circuits, 11, 72. doi:10.3389/fncir.2017.00072

Voilley, N. (2004). Acid-sensing ion channels (ASICs): new targets for the analgesic effects of nonsteroid anti-inflammatory drugs (NSAIDs). Curr Drug Targets Inflamm Allergy, 3(1), 71-79.

von Gersdorff, H., \& Borst, J. G. (2002). Short-term plasticity at the calyx of Held. Nat Rev Neurosci, 3(1), 53-64. doi:10.1038/nrn705

Vyvers, A., Schmidt, A., Wiemuth, D., \& Grunder, S. (2018). Screening of 109 neuropeptides on ASICS reveals no direct agonists and dynorphin A, YFMRFamide and endomorphin-1 as modulators. Sci Rep, 8(1), 18000. doi:10.1038/s41598-018-36125-5

Waldmann, R., Bassilana, F., de Weille, J., Champigny, G., Heurteaux, C., \& Lazdunski, M. (1997). Molecular cloning of a non-inactivating proton-gated $\mathrm{Na}+$ channel specific for sensory neurons. J Biol Chem, 272(34), 20975-20978. 
Waldmann, R., Champigny, G., Bassilana, F., Heurteaux, C., \& Lazdunski, M. (1997). A proton-gated cation channel involved in acid-sensing. Nature, 386(6621), 173-177. doi:10.1038/386173a0

Waldmann, R., \& Lazdunski, M. (1998). H (+)-gated cation channels: neuronal acid sensors in the $\mathrm{NaC} / \mathrm{DEG}$ family of ion channels. Curr Opin Neurobiol, 8(3), 418-424.

Wang, W., Yu, Y., \& Xu, T. L. (2007). Modulation of acid-sensing ion channels by $\mathrm{Cu}(2+)$ in cultured hypothalamic neurons of the rat. Neuroscience, 145(2), 631-641. doi: 10.1016/j.neuroscience.2006.12.009

Weissmann C., Salinas L.C., Gonzalez-Inchauspe C, Perissinotti P.\& Uchitel. O.D.(2017) Effect of the cytokine interleukin 6 on acid sensing ion channel (ASIC1) distribution in hippocampal neurons Society for Neuroscience abstract 50.05 / W7

Wemmie, J. A., Askwith, C. C., Lamani, E., Cassell, M. D., Freeman, J. H., Jr., \& Welsh, M. J. (2003). Acid-sensing ion channel 1 is localized in brain regions with high synaptic density and contributes to fear conditioning. J Neurosci, 23(13), 5496-5502.

Wemmie, J. A., Chen, J., Askwith, C. C., Hruska-Hageman, A. M., Price, M. P., Nolan, B. C., . . Welsh, M. J. (2002). The acid-activated ion channel ASIC contributes to synaptic plasticity, learning, and memory. Neuron, 34(3), 463-477.

Wemmie, J. A., Taugher, R. J., \& Kreple, C. J. (2013). Acid-sensing ion channels in pain and disease. Nat Rev Neurosci, 14(7), 461-471. doi:10.1038/nrn3529

Wu, L. J., Duan, B., Mei, Y. D., Gao, J., Chen, J. G., Zhuo, M., . . Xu, T. L. (2004). Characterization of acid-sensing ion channels in dorsal horn neurons of rat spinal cord. J Biol Chem, 279(42), 4371643724. doi:10.1074/jbc.M403557200

Wu, P. Y., Huang, Y. Y., Chen, C. C., Hsu, T. T., Lin, Y. C., Weng, J. Y., . . Lien, C. C. (2013). Acid-sensing ion channel-1a is not required for normal hippocampal LTP and spatial memory. J Neurosci, 33(5), 1828-1832. doi:10.1523/jneurosci.4132-12.2013

Wu, W. N., Wu, P. F., Chen, X. L., Zhang, Z., Gu, J., Yang, Y. J., . . Chen, J. G. (2011). Sinomenine protects against ischaemic brain injury: involvement of co-inhibition of acid-sensing ion channel $1 \mathrm{a}$ and L-type calcium channels. Br J Pharmacol, 164(5), 1445-1459. doi:10.1111/j.1476-5381.2011. 01487.x

Xiong, Z., Liu, Y., Hu, L., Ma, B., Ai, Y., \& Xiong, C. (2013). A rapid facilitation of acid-sensing ion channels current by corticosterone in cultured hippocampal neurons. Neurochem Res, 38(7), $1446-$ 1453. doi:10.1007/s11064-013-1045-9

Xiong, Z. G., Zhu, X. M., Chu, X. P., Minami, M., Hey, J., Wei, W. L., . . . Simon, R. P. (2004). Neuroprotection in ischemia: blocking calcium-permeable acid-sensing ion channels. Cell, 118(6), 687-698. doi: 10.1016/j.cell.2004.08.026 
Yang, L., \& Palmer, L. G. (2014). Ion conduction and selectivity in acid-sensing ion channel 1. J Gen Physiol, 144(3), 245-255. doi:10.1085/jgp.201411220

Ye, S., Yang, R., Xiong, Q., Yang, Y., Zhou, L., Gong, Y., . . Xiong, Z. (2018). Acute stress enhances learning and memory by activating acid-sensing ion channels in rats. Biochem Biophys Res Commun, 498(4), 1078-1084. doi: 10.1016/j.bbrc.2018.03.122

Yermolaieva, O., Leonard, A. S., Schnizler, M. K., Abboud, F. M., \& Welsh, M. J. (2004). Extracellular acidosis increases neuronal cell calcium by activating acid-sensing ion channel $1 \mathrm{a}$. Proc Natl Acad Sci U S A, 101(17), 6752-6757. doi:10.1073/pnas.0308636100

Zha, X. M., Wemmie, J. A., Green, S. H., \& Welsh, M. J. (2006). Acid-sensing ion channel 1a is a postsynaptic proton receptor that affects the density of dendritic spines. Proc Natl Acad Sci U S A, 103(44), 16556-16561. doi:10.1073/pnas.0608018103

Zhang, G. C., Mao, L. M., Wang, J. Q., \& Chu, X. P. (2009). Upregulation of acid-sensing ion channel 1 protein expression by chronic administration of cocaine in the mouse striatum in vivo. Neurosci Lett, 459(3), 119-122. doi: 10.1016/j.neulet.2009.05.013

Zhang, P., \& Canessa, C. M. (2002). Single channel properties of rat acid-sensitive ion channel1alpha, -2a, and -3 expressed in Xenopus oocytes. J Gen Physiol, 120(4), 553-566.

Zhang, P., Sigworth, F. J., \& Canessa, C. M. (2006). Gating of acid-sensitive ion channel-1: release of Ca2+ block vs. allosteric mechanism. J Gen Physiol, 127(2), 109-117. doi:10.1085/jgp.200509396

Ziemann, A. E., Allen, J. E., Dahdaleh, N. S., Drebot, II, Coryell, M. W., Wunsch, A. M., . . Wemmie, J. A. (2009). The amygdala is a chemosensor that detects carbon dioxide and acidosis to elicit fear behavior. Cell, 139(5), 1012-1021. doi: 10.1016/j.cell.2009.10.029.

Table 1

This article is protected by copyright. All rights reserved. 


\begin{tabular}{|c|c|c|c|c|c|}
\hline $\begin{array}{c}\text { Recomended and } \\
\text { commonly used } \\
\text { names of ASIC } \\
\text { Gene }\end{array}$ & Protein Name & $\mathrm{pH}_{50}$ activation & $\begin{array}{c}\text { Mean time } \\
\text { constant of } \\
\text { desensitization } \\
\text { at pH } 50 \text { (in } \\
\text { seconds)(1) }\end{array}$ & $\mathrm{Ca}^{2+}$ permeable(2) & $\begin{array}{c}\text { Most } \\
\text { important } \\
\text { sites of } \\
\text { expression }\end{array}$ \\
\hline ASIC1 (ACCN2) & $\begin{array}{l}\text { ASIC 1a } \\
\text { ASIC 1b }\end{array}$ & $\begin{array}{cc}\text { Homo 1a } & 5,8 \\
\text { Homo 1b } & 6.1\end{array}$ & $\begin{array}{l}0.64 \\
0.89\end{array}$ & Yes, Pna/Pca 1.8 & $\begin{array}{c}\text { CNS/PNS } \\
\text { PNS }\end{array}$ \\
\hline ASIC2 (ACCN1) & $\begin{array}{l}\text { ASIC 2a } \\
\text { ASIC 2b }\end{array}$ & $\begin{array}{c}\text { Homo 2a } 4.5 \\
\text { NA }\end{array}$ & 1.4 & & CNS/PNS \\
\hline & & $\begin{array}{l}\text { Heter1a/2b } 6.2 \\
\text { Heter1a/2a } 5.5\end{array}$ & $\begin{array}{l}1.1 \\
1.3\end{array}$ & $\begin{array}{l}\text { Yes, Pna/Pca } 4.1 \\
\text { Low ,Pna/Pca } 25\end{array}$ & CNS/PNS \\
\hline ASIC3 (ACCN3) & ASIC 3 & Homo 3 & 0.29 & & PNS \\
\hline ASIC4 ( ACCN4) & ASIC 4 & NA & & & CNS/PNS \\
\hline ASIC5 ( ACCN5) & $\begin{array}{c}\text { ASIC } 5 \\
\text { (BASIC) }\end{array}$ & NA & & & \\
\hline
\end{tabular}

Table 1. Modified from Grunder and Pusch (2015) and Kellemberger and Schild (2015). Values obtained from (1) Hesselager M, Timmermann DB, Ahring PK (2004)

(2) Sherwood TW, Lee KG, Gormley MG, and Askwith CC (2011) 

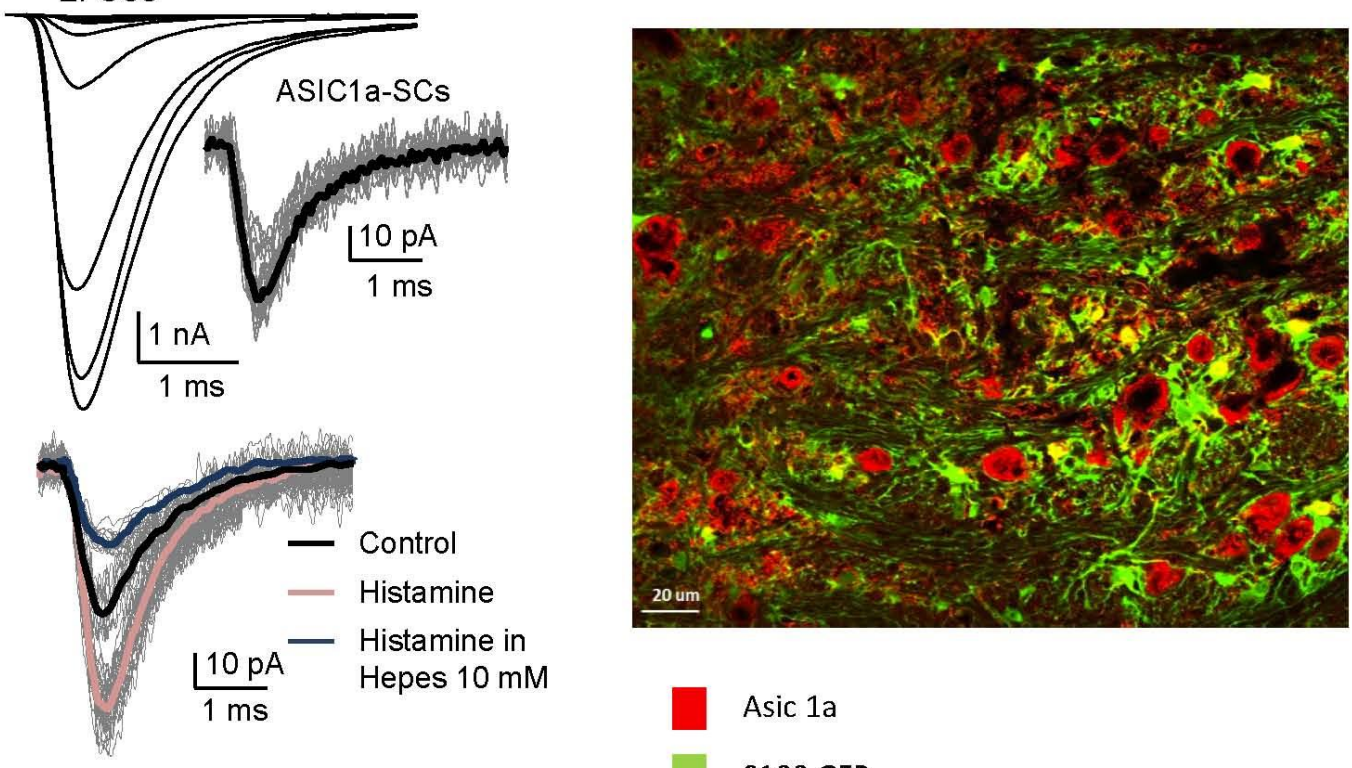

Asic 1a

S100 GFP

This article is protected by copyright. All rights reserved. 


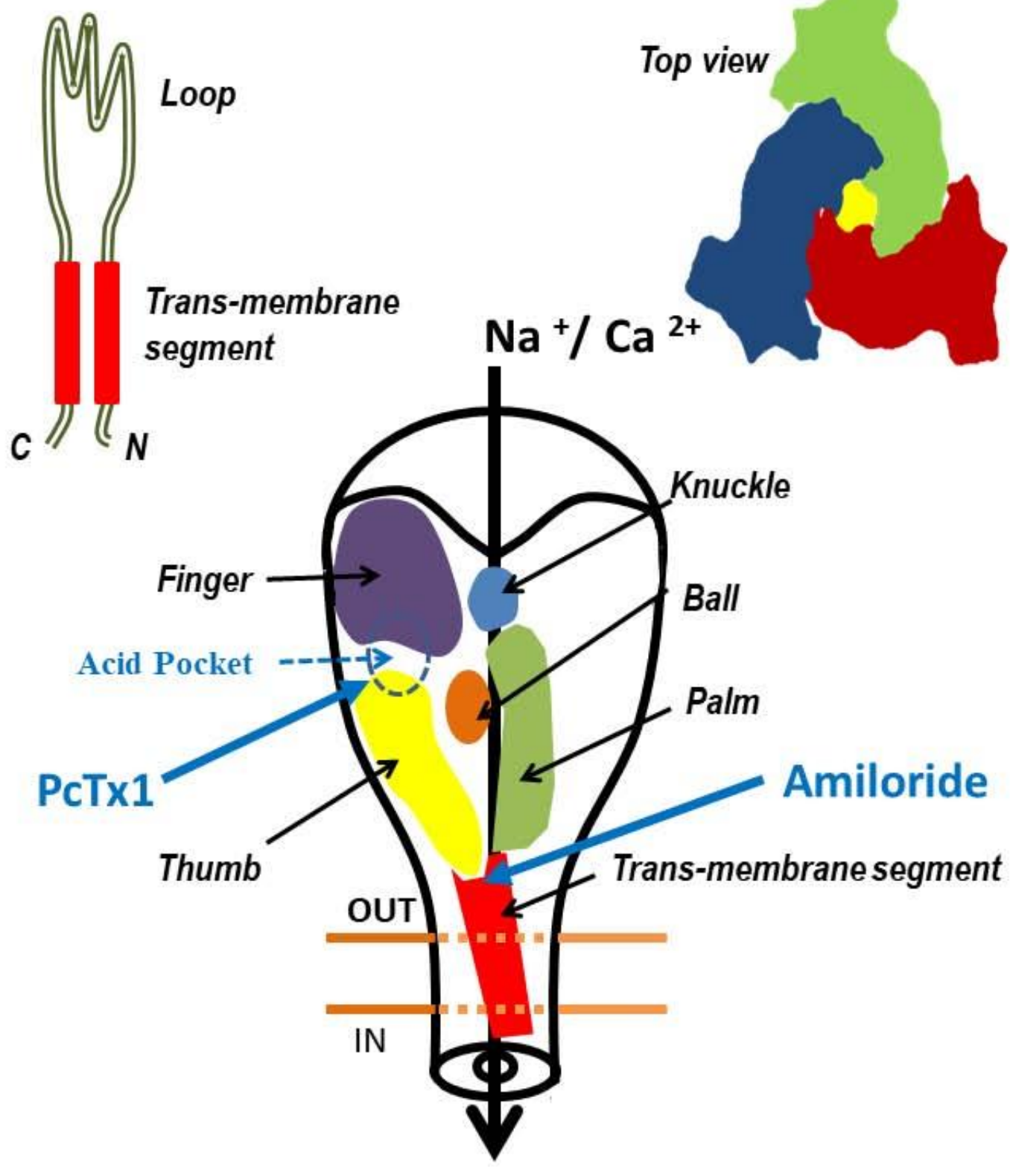

